\title{
Biomassa e atividade microbianas em áreas de caatinga sob diferentes densidades de caprinos
}

\author{
Rômulo Gil de Luna', João Gil de Luna ${ }^{2}$, Albericio Pereira de \\ Andrade $^{3}$, Jacob Silva Souto ${ }^{4}$ e Krystyna Gorlach-Lira ${ }^{5}$
}

\begin{abstract}
${ }^{1}$ Unidade Acadêmica de Ciência e Tecnologia Ambiental. Centro de Ciências e Tecnologia Agroalimentar. Universidade Federal Campina Grande. Rua Jairo Vieira Feitosa, 1770. Pereiros. Pombal-PB, Brasil (CEP 58840-000). E-mail: romulo.gil.luna@gmail.com.

${ }^{2}$ Departamento de Estatística. Universidade Estadual da Paraíba. Rua Juvêncio Arruda, S/N. Bodocongó. Campina Grande-PB, Brasill (CEP 58109-790).

${ }^{3}$ Universidade Federal Rural de Pernambuco. Unidade Acadêmica de Garanhuns. Avenida Bom Pastor, S/No. Boa Vista. Garanhuns-PE, Brasil (CEP 55292-270).

${ }^{4}$ Unidade Acadêmica de Engenharia Florestal. Universidade Federal de Campina Grande. Av. Universitária, S/No. Santa Cecília. Patos-PB, Brasil (CEP 58700-970).

${ }^{5}$ Departamento de Biologia Molecular. Centro de Ciências Exatas e da Natureza. Universidade Federal da Paraíba. Rua Juvêncio Arruda, S/N. Bodocongó. Campina Grande-PB, Brasill (CEP 58051-900).
\end{abstract}

Resumo. 0 crescente aumento populacional tem forçado o homem a exigir cada vez mais do campo circundante. Esta exigência tem levado à degradação de muitas áreas outrora produtivas. Frente aos avanços dessas áreas, torna-se imperativa à busca de elementos, preferencialmente menos onerosos e de fácil aquisição, que possam ser utilizados como indicadores dos estádios dessa degradação. Sendo assim, objetivou-se aqui investigar alguns parâmetros microbiológicos de solos, visando sua utilização como indicadores ecológicos de ambientes degradados ou em processo de desertificação, em áreas de caatinga sob diferentes densidades de caprinos, no Cariri da Paraíba, Brasil. 0 estudo foi realizado na Fazenda Experimental Bacia Escola ( $7^{\circ} 24^{\prime} \mathrm{S}$; $\left.36^{\circ} 32^{\prime} \mathrm{W}\right)$, em São João do Cariri. A densidade de caprinos foi de 3 animais.ha-1 e 1,5 animais.ha-1 ${ }^{-1}$, nas áreas I e II, respectivamente; e sem animais nas áreas III e IV. Foram plotadas 30 parcelas de $10 \mathrm{~m} \times 10 \mathrm{~m}$ em cada área experimental, distribuídas ao longo de três linhas de faixas semiparalelas. Durante dois anos foram, a cada 45 dias, determinadas a atividade decompositora dos micro-organismos $(\mathrm{AD})$, a biomassa microbiana (BM), a respiração basal (RB), o quociente metabólico $\left(\mathrm{qCO}_{2}\right)$ e a relação do carbono microbiano como parte do carbono orgânico total do solo $\left(\mathrm{C}_{\text {mic }}: \mathrm{C}_{\text {org }}\right)$. A atividade decompositora foi estimada a partir de taxas de decomposição celulolítica, utilizando-se saquinhos de náilom com abertura de malha de $45 \mu \mathrm{m}$, enterrados a $20,0 \mathrm{~cm}$ de profundidade no solo. A BM e a RB foram estimados a partir do método de fumigação-incubação, sendo o $\quad \mathrm{qCO}_{2}$ e $\quad$ o $\mathrm{C}_{\text {mic }}: \mathrm{C}_{\mathrm{org}}$
Recebido:

$31 / 12 / 2018$

Aceito:

23/04/2019

Publicado:

$30 / 04 / 2019$

Acesso aberto

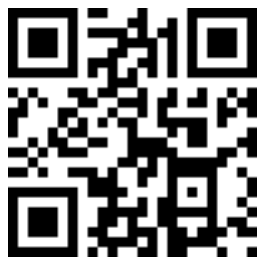

\footnotetext{
ORCID

(1) 0000-0002-8350-5615 Rômulo Gil de Luna

(1) 0000-0002-1820-3979 João Gil de Luna
} 
determinados a partir dos valores de BM e RB calculados. Também foram feitas anáises de solo das áreas estudadas. Para verificar os efeitos dos níveis dos tratamentos $\mathrm{T}_{1}, \mathrm{~T}_{2}, \mathrm{~T}_{3}$ (ano de 2012) e $T_{1}, T_{2}, T_{3}$ e $T_{4}$ (ano de 2013) sobre a variável resposta atividade decompositora (AD) foi realizada uma análise de variância univariada considerando um delineamento inteiramente casualizado com medidas repetidas no tempo (a cada 45 dias), com 30 repetições por tratamento. 0 plano experimental usado para a coleta das informações relativas aos dados de $\mathrm{BM}, \mathrm{AR}, \mathrm{qCO}_{2}$ e $\mathrm{C}_{\text {mic }}$ : $\mathrm{C}_{\text {org }}$ foi compatível com um delineamento em blocos casualizados (ou experimento com dois fatores sem interação) em que as épocas de avaliação foram consideradas como sendo os ambientes homogêneos (ou blocos) e em cada uma delas foi instalado um conjunto completo de tratamentos. A análise de química e fertilidade revelou que o solo da área III apresentou o $\mathrm{pH}$ mais próximo da neutralidade, os maiores teores dos macronutrientes $(\mathrm{P}, \mathrm{K}, \mathrm{Ca}$ e $\mathrm{Mg}$ ) e valores de CTC, V\% e SB do que o solo das áreas I, II e IV, sugerindo que aquele apresenta as melhores condições ao desenvolvimento de pastagens introduzidas ou de reabilitação da vegetação nativa. Os resultados de $\mathrm{AD}$ não se mostraram uteis como indicadores biológicos de áreas degradadas pelo pastejo caprino, pois em algumas épocas de avaliação, AD foi maior nos tratamentos $\mathrm{T}_{1} \mathrm{e}$ $\mathrm{T}_{2}$ e em outras, nas testemunhas $\left(\mathrm{T}_{3}\right.$ e $\left.\mathrm{T}_{4}\right)$. Os parâmetros microbiológicos aqui estudados, com ênfase para a $\mathrm{BM}$, a RB, o $\mathrm{qCO}_{2}$ e a relação $\mathrm{C}_{\text {mic }}: \mathrm{C}_{\text {org }}$ (2012) e $\mathrm{BM}$ e $\mathrm{C}_{\text {mic }}: \mathrm{C}_{\text {org }}$ (2013) mostraram-se sensíveis à degradação pelo pastejo, podendo ser utilizados como indicadores ecológicos de áreas degradadas.

Palavras-chave: Semiárido; Desertificação; Microbiota edáfica; Indicadores ecológicos.

\footnotetext{
Abstract. Biomass and microbial activity in areas of caatinga under different densities of goats. The growing population increase has forced the man to require more and more of the surrounding field. This requirement has led to the degradation of many formerly productive areas. Forward to the advances of these areas, it becomes imperative to search for less costly and elements of easy acquisition, which can be used as indicators of the stages of this degradation. Thus, the objective here was to investigate some microbiological parameters of soils, aiming their use as ecological indicators of degraded environments or in process of desertification in areas of caatinga under different densities of goats in the Cariri of the Northeastern State of Paraíba, Brazil. The study was carried out at the Experimental Farm School Bay ( $7^{\circ} \mathrm{S} 24^{\prime} \mathrm{S}, 36^{\circ} 32^{\prime} \mathrm{W}$ ), in São João do Cariri. The density of goats was of 3 animals/ha and 1.5 animal/ha, in the areas I and II, respectively; and without animals in areas III and IV. Thirty plots of $10 \mathrm{~m} \times 10 \mathrm{~m}$ in each experimental area were plotted and distributed over three lines of semiparalels tracks. For two years, every 45 days, decomposition activity of microorganisms (AD), microbial biomass (BM), the basal
}

(D) 0000-0002-1223-394X Albericio Pereira de Andrade

D 0000-0002-9787-8623 Jacob Silva Souto

(1) 0000-0002-7892-2705 Krystyna Gorlach-Lira 
respiration $(\mathrm{RB})$, the metabolic quotient $\left(\mathrm{C}_{\mathrm{mic}}\right)$ were estimated and the relationship of microbial carbon as part of the total soil organic carbon $\left(\mathrm{C}_{\text {mic }}: \mathrm{C}_{\text {org }}\right.$ ) was calculated. Decomposition activity was estimated from rates of cellulolytic decomposition, using nylon bags with $45 \mu \mathrm{m}$ mesh opening, buried at $20.0 \mathrm{~cm}$ deep in the soil. BM and the RB were estimated from the method of fumigation-incubation, and $\mathrm{qCO}_{2}$ being the $\mathrm{C}_{\text {mic }}: \mathrm{C}_{\text {org }}$ determined from the values of BM and RB calculated. Soil analyses were also made of the areas studied. To check the effects of the levels of the treatments $T_{1}, T_{2}, T_{3}$ (year 2012) and $T_{1}, T_{2}, T_{3}$ and $T_{4}$ (year of 2013) on the response variable decomposition activity (AD) was a univariate analysis of variance was performed by taking in account a completely randomized design with repeated measurements in time (every 45 days), with 30 repetitions per treatment. The experimental plan used for the collection of information concerning data of $\mathrm{BM}, \mathrm{AR}, \mathrm{qCO}_{2}$ and $\mathrm{C}_{\text {mic }}$ : $\mathrm{C}_{\text {org }}$ was compatible with a randomized block design (or experiment with two factors without interaction) in which the times of assessment were considered as being homogeneous environments (or blocks) and in each one of them was installed a complete set of treatments. Fertility and chemical analysis revealed that the soil of the area III presented the $\mathrm{pH}$ closer to neutrality, the largest concentrations of macronutrients $(\mathrm{P}, \mathrm{K}, \mathrm{Ca}$ and $\mathrm{Mg}$ ) and CEC values, V\% and SB than the soil of the areas I, II and IV, suggesting that the soil of area III presents the best conditions for the development of pasture introduced or rehabilitation of native vegetation. The results of $\mathrm{AD}$ did not prove to be useful as biological indicators of areas degraded by grazing goats, because in some evaluation times, $\mathrm{AD}$ was greater in treatments $\mathrm{T}_{1}$ and $\mathrm{T}_{2}$ and in others, the witnesses ( $\mathrm{T}_{3}$ and $\mathrm{T}_{4}$ ) were the greatest. The microbiological parameters here studied, with emphasis to the $\mathrm{BM}$, the $\mathrm{RB}$, the $\mathrm{qCO}_{2}$ and $\mathrm{C}_{\text {mic }}: \mathrm{C}_{\text {org }}(2012)$ and $\mathrm{BM}$ and $\mathrm{C}_{\text {mic }}: \mathrm{C}_{\text {org }}$ (2013) showed to be susceptible to degradation by grazing, and can be used as ecological indicators of degraded areas.

Keywords: Semi-arid; Desertification; Soil microbiota; Ecological indicators.

\section{Introdução}

0 crescimento populacional humano tem exigido cada vez mais alimentos do campo circundante e, consequentemente, a expansão da fronteira agrícola e da pecuária passou a ser uma necessidade cada vez mais crescente. De acordo com Graziano Neto (1986), para atender a essa exigência, a tão aclamada moderna agricultura reuniu um amplo elenco de práticas ambientalmente incorretas, econômicamente duvidosas e socialmente injustas.
Dentre as práticas implementadas para aumentar a produção de frutas, verduras, legumes e pastos foram adotados 0 desmatamento e a subsequente correção topográfica, seguidas pela aragem, gradagem, subsolagem, irrigação, drenagem, adubação, calagem, além do uso de uma vasta gama de defensivos agrícolas para controlar as populações de concorrentes indesejados.

A adoção dessas práticas tem causado profundas alterações nas propriedades físicas, químicas e biológicas dos solos, transformando 
áreas outrora produtivas em áreas degradadas e de difícil recuperação. Esta degradação tem como consequência a redução da produtividade devido à perda de solos e de seus constituintes orgânicos, inorgânicos e biológicos.

Hodiernamente, segundo GamaRodrigues e De-Polli (2000), a ciência do solo tem como maior desafio demonstrar a relação existente entre 0 funcionamento sustentável do ecossistema e os níveis de atividade biológica nele encontrados. Dentro desta perspectiva a medida mais prática do "status biológico" do solo é a biomassa microbiana e sua atividade. Desta maneira, segundo os referidos autores, o estudo deste compartimento vivo deve tornar-se prática rotineira em estudos de ciclagem da matéria orgânica e de nutrientes, tendo como enfoque a sua contribuição na decomposição e mineralização da necromassa e, consequentemente, na fertilização do solo.

No semiárido do Nordeste brasileiro, onde a pecuária tem maiores chances de desenvolvimento e sustentabilidade que a agricultura, a degradação dos recursos naturais também tem sido provocada pelo aumento da intensidade de uso do solo e redução da cobertura vegetal nativa (Menezes e Sampaio, 2002), como também pelo pastejo permanente ali praticado, muitas vezes com taxa de lotação acima da capacidade de suporte do ecossistema (Sampaio, 2010).

De acordo com Martins et al. (2010) muitas são as áreas do semiárido brasileiro que se encontram em processo de degradação decorrentes de causas naturais ou provocada pelo homem, fazendo-se necessária a utilização de ferramentas, preferencialmente de baixo custo, que indiquem os estádios dessa degradação, a fim de viabilizar um manejo adequado e a recuperação dessas áreas.

Dentre os indicadores do solo capazes de representar a comunidade microbiana, o C microbiano destaca-se devido à sua relação com a matéria orgânica, ciclagem de nutrientes e fluxo de energia (De-Polli e Guerra, 1999).

Atualmente, poucos são os trabalhos que envolvem variáveis microbianas de solos na região semiárida visando sua utilização como indicadores de áreas em processo de degradação, de modo a fornecer subsídios para a prevenção desse processo e contribuir para a elaboração de estratégias de recuperação de áreas já degradadas.

Deste modo, o objetivo desta pesquisa foi analisar a variabilidade de atributos microbianos de solos, visando a sua utilização como indicadores de ambientes degradados ou em processos de degradação, em áreas de Caatinga sob diferentes densidades de caprinos na região semiárida do Cariri da Paraíba.

\section{Material e método}

\section{estudo \\ Localização das áreas de}

Os estudos foram realizados na Estação Experimental Bacia Escola, de propriedade da Universidade Federal da Paraíba ( $7^{\circ} 23^{\prime} 30^{\prime \prime} \mathrm{S}$ e $\left.36^{\circ} 31^{\prime} 59^{\prime \prime} \mathrm{W}\right)$, administrada pelo Centro de Ciências Agrárias (CCA), localizada no município de São João do Cariri-PB, microrregião do Cariri Oriental, mesorregião da Borborema Central (Figura 1). 


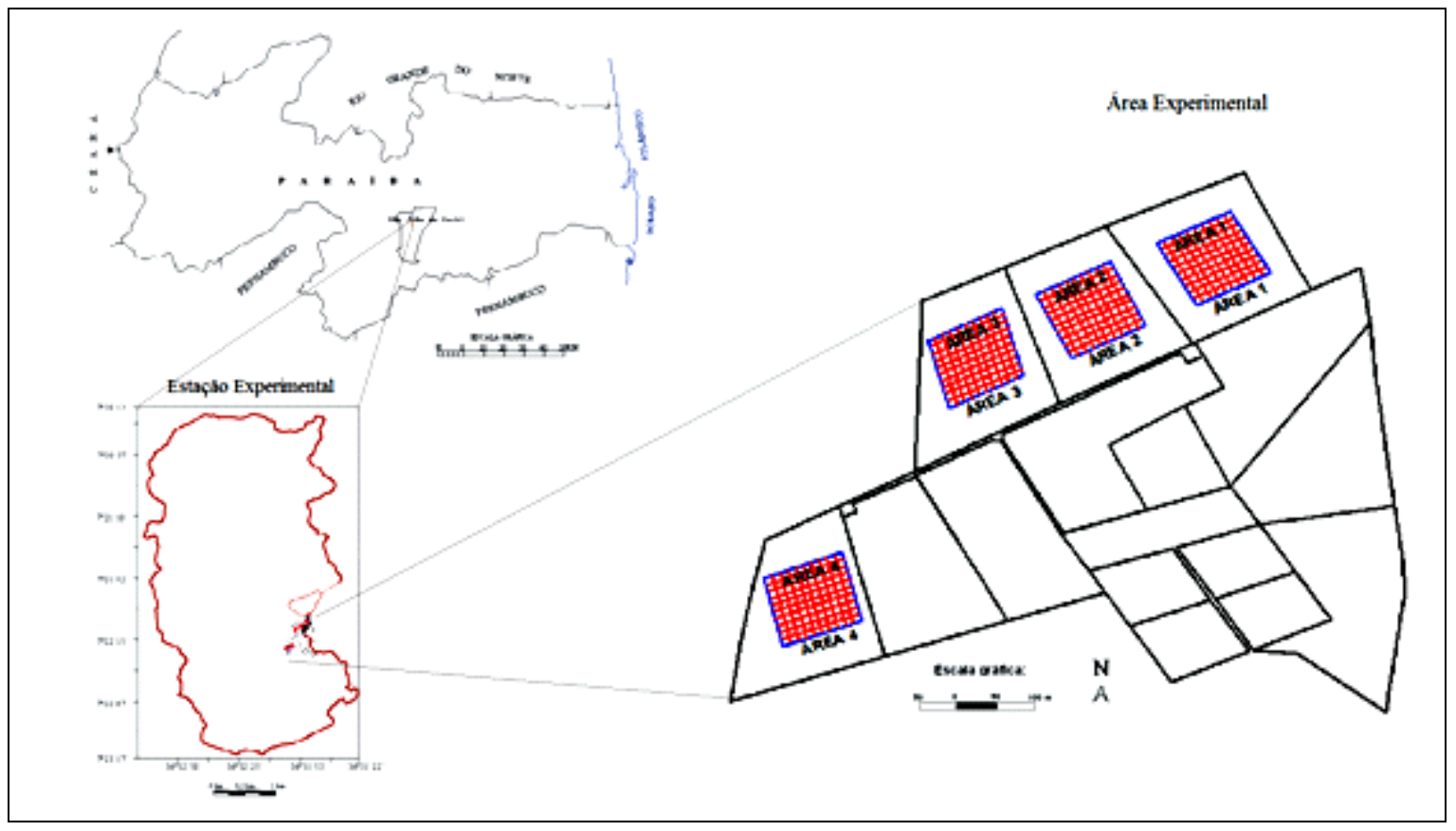

Figura 1. Mapa do Estado da Paraíba, com ênfase para as áreas experimentais localizadas na Fazenda Experimental Bacia Escola, Município de São João do Cariri.

O Município de São João do Cariri caracteriza-se pela elevada semiaridez, baixo índice pluviométrico e acentuado déficit hídrico (Andrade et al., 1999).

Os LUVISSOLOS Crômicos Vérticos, os VERTISSOLOS e os NEOSSOLOS líticos, são os solos predominantes na Bacia Escola (Chaves, et al., 2000). As texturas predominantes nas áreas experimentais são franco arenosa e franco argiloarenosa.

No primeiro ano de pesquisa (2012) foram utilizadas três áreas experimentais $\left(\mathrm{T}_{1}, \mathrm{~T}_{2}\right.$ e $\left.\mathrm{T}_{3}\right)$ e no segundo ano, quatro áreas $\left(\mathrm{T}_{1}, \mathrm{~T}_{2}, \mathrm{~T}_{3} \mathrm{e} \mathrm{T}_{4}\right)$. Estas áreas contíguas são uma subdivisão de uma área maior, não havendo praticamente diferenças entre elas do ponto de vista fitofisionômico (Luna et al., 2018). Ao longo dos anos elas sofreram as mesmas interferências antrópicas (corte de madeira, cultivo de subsistência, pastejo extensivo, e outros). Atualmente elas são constituídas de Caatinga arbóreo-arbustiva, aberta e, nas áreas I e II, sob o pastejo permanente de caprinos.

Para avaliar os efeitos do pastejo sobre a microbiota edáfica, foram adotados os seguintes tratamentos: $\mathrm{T}_{1}$ (10 animais $/ 3,3$ ha; $\approx 3$ animais $/ \mathrm{ha}$ ), $\mathrm{T}_{2}$ (5 animais/3,34 ha; $\approx 1,5$ animais/ha), $\mathrm{T}_{3}$ e $\mathrm{T}_{4}$ (Controle - 3,3 ha, sem animais).

Os caprinos utilizados no experimento (indivíduos masculinos, adultos sem padrão de raça definido) permaneceram nas áreas do início ao fim dos experimentos (2012 e 2013). Estes foram substituídos sempre que necessário (por motivos de morte, doenças ou outras causas). Estas condições experimentais foram implantadas em agosto de 2007 e, desde então, os caprinos têm se alimentado apenas de material vegetal proveniente da própria Caatinga (inclusive de serapilheira), porém recebendo uma suplementação diária de 1,5 a 3\% de seu peso vivo em ração preparada (farelos, xerém, ureia, etc.). 


\section{fertilidade}

Análises de solos: química e

Das amostras de solo coletadas para as análises microbiológicas (biomassa e atividade microbianas) foram retiradas sub-amostras para as análises de química e fertilidade. Estas amostras foram coletadas do horizonte mineral $(0-20,0 \mathrm{~cm})$ de quinze parcelas de cada área experimental, adotando-se o critério de coleta do tipo parcelas alternadas. Tomou-se o cuidado de não coletar solos daqueles locais conhecidos por áreas de dormidas (ambientes de onde os caprinos partem e para onde retornam após satisfazerem suas necessidades diárias), uma vez que estes locais são muito ricos em esterco e urina. Estas análises foram efetuadas pelo Laboratório de Solos, pertencente ao Centro de Ciências Agrárias da Universidade Federal da Paraíba, Campus III, Areia-PB.

\section{Coleta e tratamento das amostras de solo para a determinação da biomassa e da atividade microbianas}

As amostras de solo foram coletadas do horizonte mineral, na profundidade de 0,0-20,0 cm, tendo-se o cuidado de afastar toda serapilheira superficial (folhas, galhos e outras partes caídas das plantas) até atingir o referido horizonte. Foram coletadas quinze amostras por área, adotando-se o critério de coleta em parcelas alternadas, para todas as áreas experimentais. Estas amostras foram colocadas em sacos plásticos, tomando-se cuidado de deixar bastante ar em seu interior para manter o suprimento de oxigênio para as populações microbianas nele contidas. Os sacos após etiquetados foram levados para o laboratório e as amostras foram imediatamente processadas (Figura 2).

Em laboratório as amostras foram homogeneizadas e peneiradas $(<2 \mathrm{~mm})$ sem forçar a passagem do solo e, utilizando-se de uma pinça, toda a matéria orgânica visível (fragmentos de raízes, folhas, larva de artrópodes, e outros tipos de necromassa) foi cuidadosamente removida.

Em seguida, as amostras foram novamente colocadas em sacos plásticos, deixando-se bastante ar em seu interior. Depois elas foram pré-incubadas em ambiente escuro com ar condicionado (temperatura de aproximadamente $25{ }^{\circ} \mathrm{C}$ ), durante 5 a 7 dias, para reduzir os efeitos do peneiramento, conforme sugestões de Powlson (1980).

Após a pré-incubação, foram retiradas alíquotas para a determinação do conteúdo de água e da capacidade de saturação dos solos (CS) provenientes de cada área experimental.

No dia que antecede à incubação, cada solo teve sua umidade corrigida para $40 \%$ de sua CS, adotando-se os procedimentos descritos por Grisi (1995), que sugere cuidadosa homogeneização do solo após umedecido. Utiliza-se tal valor de CS porque, sob condições mais úmidas (60\%-80\%), a matéria orgânica é decomposta mais lentamente em virtude de um inadequado fornecimento de $\mathrm{O}_{2}$. Nestas condições, o metabolismo microbiano torna-se anaeróbico e, portanto, fermentativo, havendo diminuição da liberação de $\mathrm{CO}_{2}$, em decorrência da produção de outros gases, como $\mathrm{CH}_{4}$ e alcoóis (Minhone e Cerri, 1987a; Minhone e Cerri, 1987b). Os maiores valores de respiração por estes citados autores foram em solos com $40 \%$ de umidade da capacidade de saturação (CS).

Para a determinação do conteúdo de água no solo foram pesadas cinco amostra de $30 \mathrm{~g}$ de solo fresco (proveniente de cada área experimental). Estas foram colocadas em estufa a $105^{\circ} \mathrm{C}$ durante $24 \mathrm{~h}$; após esse período, as amostras foram pesadas e calculadas as médias da perda de água, em porcentagem.

A determinação do conteúdo de água é um parâmetro imprescindível, pois é a partir dela que é calculado o déficit de umidade de uma determinada amostra de solo. Por exemplo: 
Se a capacidade de saturação de um determinado solo é $30 \%$;

Então, $40 \%$ dessa capacidade de saturação é $12 \%$;

Se o teor de umidade desse solo, no momento da coleta for de $2 \%$; e

Então, o solo tratado encontra-se com um déficit de umidade de $10 \%$.

Portanto, deve-se adicionar $10 \%$ de água a este solo caso o pesquisador deseje trabalhar com $40 \%$ da capacidade de saturação.

Se por acaso, no momento da coleta, o pesquisador desconfiar que o solo encontra-se acima da capacidade de saturação desejada, é preferível não coletá-lo ou, se coletá-lo, esperar que ele perca água naturalmente em laboratório, até atingir as condições desejadas.

Para a determinação da capacidade de saturação (CS) foi utilizado o método de Allen (1974), descrito por Grisi (1995) o qual, resumidamente, constitui-se nos seguintes passos:

1-Secar um cadinho de Gooch e pesá-lo;

2- Mergulhá-lo em água para saturar o filtro de porcelana, removendo o excesso de água no vidro compapel absorvente, e pesá-lo;

3- Transferia $25 \mathrm{~g}$ do solo coletado para o cadinho;

4- Mergulhar o cadinho com solo, em água, mantendo o nível da água pouco acima do filtro de porcelana;

5- Deixar imerso por $2 \mathrm{~h}$;
6- Remover, secando rápidamente a superfície externa do cadinho, pesando-o em seguida;

7- Secar a $105^{\circ} \mathrm{C}$ por, pelo menos $6 \mathrm{~h}$; o cadinho;

8- Resfriar em dessecador e pesar

9- Efetuar o seguinte cálculo: Capacidade de saturação

$(\%)=(A-B+C-D /(D-A)$ Onde:

$A=$ Peso do cadinho seco;

$\mathrm{B}=$ Peso do cadinho com o

filtro de porcelana umedecido; $\mathrm{C}=$ Peso do cadinho com o solo saturado;

$\mathrm{D}=$ Peso do cadinho como

o solo seco.

\section{Biomassa microbiana do solo}

A biomassa microbiana (BM) foi estimada segundo o método de fumigação-incubação (FI) de Jenkinson e Powlson (1976), conforme apresentado em Grisi e Gray (1986) e Vance et al. (1987a). Este método baseia-se na eliminação das populações microbianas de uma amostra de solo, por um agente fumigante, seguido de inoculação de micro-organismos vivos (amostra de solo fresca) e na medicão do $\mathrm{CO}_{2}$ liberado por estes que se alimentam dos microorganismos mortos, durante um período de 10 dias. Utiliza-se como controles amostras de solo não fumigadas. A biomassa microbiana, representada pelo carbono microbiano pode, então, ser estimada pela equação:

\section{$\mathrm{BM}=(\mathrm{X}-\mathrm{X}) / \mathbf{k C}$}

Onde:

$\mathrm{BM}$ : biomassa microbiana (em mg de $\mathrm{C}-\mathrm{CO}_{2} .100 \mathrm{~g}^{-1}$ de solo seco em estufa);

$\mathrm{X}: \mathrm{CO}_{2}$ emanado das amostras de solo fumigadas;

$\mathrm{x}: \mathrm{CO}_{2}$ emanado das amostras de solo não fumigadas;

$\mathrm{kc}$ : fator de mineralização do carbono $\left(0,45\right.$ a $\left.25^{\circ} \mathrm{C}\right)$. Valor este, recomendado por Jenkinson e Ladd (1981) e Vance et al. (1987b), para solos com pH acima de 4,5, como os dos solos aqui estudados (Tabela 1). 


\section{Fumigação e incubação}

Para a determinação da BM foi utilizado o método de fumigaçãoincubacão de Jenkinson e Powlson (1976), cujo procedimento (resumido) foi o seguinte: foram colocadas amostras de solo (100 g cada uma, com base em peso fresco) em recipientes de alumínio (latinhas). De cada solo (proveniente de cada área experimental) foram pesadas oito amostras, totalizando, portanto, 32 amostras. Metade das amostras de solo de cada área foi colocada em câmaras úmidas preparadas a partir de um dessecador de vidro e foram submetidas à fumigação com clorofórmio livre-deálcool (cloreto de etila), usando-se vácuo produzido pela passagem de água, a partir de uma torneira. As amostras foram deixadas em contato com o vapor do clorofórmio por $24 \mathrm{~h}$, sendo, depois, o vapor totalmente removido, limpando-se a câmara úmida e submetendo-as novamente ao vácuo de torneira. As amostras não fumigadas foram deixadas em outras câmaras úmidas para a incubação. Estes dois conjuntos de amostras permaneceram no escuro durante $24 \mathrm{~h}, \quad$ em temperatura aproximadamente de $25^{\circ} \mathrm{C}$, mantidas por um ar-condicionado.

Após a remoção do fumigante foi introduzido em cada solo fumigado, $10 \%$ de solo não fumigado (com microorganismos vivos) dos respectivos solos tratados, segundo recomendação de Chapman (1987), para solos com acidez na faixa de $\mathrm{pH} 4,5$ a 6,0. Cada amostra foi colocada em câmara de vidro (com capacidade 3 litros) e nesta foram colocados $10 \mathrm{ml}$ de $\mathrm{KOH} \mathrm{0,5} \mathrm{M,} \mathrm{em} \mathrm{um}$ béquer de $100 \mathrm{ml} 0$ mesmo procedimento foi adotado para cada amostra de solo não fumigada. Todas as câmaras foram mantidas hermeticamente fechadas, no escuro, a uma temperatura aproximada de $25{ }^{\circ} \mathrm{C}$ durante dez dias de incubação.

Após esse período, o $\mathrm{CO}_{2}$ emanado das amostras de solo fumigadas e não fumigadas foi absorvido por uma solução de $\mathrm{KOH}$ 0,5 M e, em seguida, dosado com $\mathrm{HCl}$ 0,1 M.

Para se determinar a quantidade de $\mathrm{CO} 2$ que foi absorvida pela solução de $\mathrm{KOH}$ 0,5 M (durante os dez dias de incubação), após a titulação com $\mathrm{HCl}$ 0,1 M, foram feitos os seguintes cálculos:

\section{$m g \mathrm{CO}_{2}=(\mathrm{A}-\mathrm{B}) \times 2 \times 2,2$}

onde:

$\mathrm{A}=$ média obtida pela diferença entre a primeira e a segunda viragem das amostras;

$\mathrm{B}=$ média obtida pela diferença entre a primeira e a segunda viragem do controle ou testemunha;

$\mathrm{X} 2=$ porque o $\mathrm{HCl}$ 0,1 M adicionado, titulou apenas metade do carbonato do frasco experimental, ou seja, da amostra;

$\mathrm{X} 2,2=$ sendo o equivalente-grama do $\mathrm{CO}_{2}$ igual a $44 / 2=22$ e como se usou $\mathrm{HCl} 0,1$ $M$ (decinormal), este equivalente torna-se então: $22 / 10=2,2$.

Por este método, de acordo com Grisi (1978), o produto obtido deve ser multiplicado por $4 / 3$, alertando ele que assim não procedendo, só se conseguirá $3 / 4$ do $\mathrm{CO}_{2}$ depreendido das amostras, ou seja, $75 \%$ da amostra.

De posse do valor obtido, estimase o carbono de $\mathrm{CO}_{2}$ da seguinte maneira:

Sabendo-se que o peso molecular do $\mathrm{CO}_{2}$ é $44 \mathrm{mg}$, conclui-se que $12 \mathrm{mg}$ dessa massa é de carbono $\left(\mathrm{PM}\right.$ do $\mathrm{CO}_{2}=$
$44 \mathrm{mg}$, onde $\mathrm{C}=12 \mathrm{mg}$ e $\mathrm{O}=16 \mathrm{mg}$ ). Portanto, utilizando-se uma regra de três simples, poder-se-á calcular quantos $\mathrm{mg}$ de $\mathrm{C}-\mathrm{CO}_{2}$ foram emanados de cada amostra de solo. Exemplo: 
Se em 44 mg CO 2 há 12 mg de C$\mathrm{CO}_{2}$

Então em $34 \mathrm{mg}$ de $\mathrm{CO}_{2}$, por exemplo, há $\mathrm{X} \mathrm{mg}$ de $\mathrm{C}-\mathrm{CO}_{2}$, onde

$\mathrm{X}=9,27 \mathrm{mg}$ de $\mathrm{C}-\mathrm{CO}_{2}$

Este valor, sendo dividido pelo fator de mineralização do carbono (kc), representará a biomassa microbiana da amostra de solo que será finalmente expressa por $100 \mathrm{~g}$ de solo seco em estufa (S. E.), ou seja, a BM será expressa em mg de C- $\mathrm{CO}_{2} .100 \mathrm{~g}^{-1} \mathrm{~g} . \mathrm{m}^{-2}$ de solo S.E.

\section{Atividade microbiana do solo}

A atividade microbiana foi estimada a partir de taxas de decomposição celulolítica, utilizando-se algodão higrófilo como substrato para os micro-organismos e também através da medição do $\mathrm{CO}_{2}$ emanado de amostras de solo não-fumigadas e incubadas in vitro. 0 primeiro tipo é conhecido como atividade decompositora (AD) ou atividade potencial e, o segundo, como atividade respiratória (AR) ou atividade real, também conhecida como respiração basal.

\section{Atividade decompositora}

$A$ atividade decompositora (AD) ou atividade microbiana potencial, foi estimada segundo o método de decomposição celulolítica proposto por Parkinson et al. (1971), utilizado por Luna e Grisi (1996), Luna e Coutinho (2008) e Luna et al. (2008). Por este método, amostras contendo $1,0 \mathrm{~g}$ de algodão higrófilo (celulose pura), previamente secas em estufa $\left(105{ }^{\circ} \mathrm{C}\right.$ por $24 \mathrm{~h}$ ), foram colocadas em sacos confeccionados com náilon, com abertura de malha de aproximadamente $45 \mu \mathrm{m}$ e enterrados na profundidade de $20,0 \mathrm{~cm}$ (Figura 2).

Ao longo de cada linha de faixa, foram enterradas 10 amostras, distando entre si aproximadamente $10,0 \mathrm{~m}$, totalizando 30 amostras em cada área experimental.

A cada 45 dias, essas amostras foram coletadas e renovadas. Os sacos, após coletados, foram lavados em água corrente, e as amostras neles contidas foram removidas, secas em estufa $\left(105^{\circ} \mathrm{C}\right.$ por $\left.24 \mathrm{~h}\right)$ e determinadas sua perda de peso seco em balança analítica de precisão (0,1 g). A unidade adotada para esse parâmetro foi em g. ano-1.

\section{Atividade respiratória}

Para estimar a atividade respiratória, aqui chamada respiração basal (RB) ou atividade microbiana real, utilizou-se o volume de $\mathrm{CO}_{2}$ respirado de amostras de solo não perturbadas (nãofumigadas), conforme sugestões de Lynch e Panting (1981). Este parâmetro vem sendo rotineiramente utilizada em investigações sobre microbiologia de solo até os dias atuais.

De acordo com os referidos autores, a RB pode ser estimada a partir do $\mathrm{CO}_{2}$ emanado de amostras de solo não-fumigadas durante o método de fumigação-incubação de Jenkinson e Powlson (1976), conforme apresentado em Grisi e Gray (1986) e Vance et al. (1987a).

Amostras de solo não-fumigadas foram submetidas a uma incubação de 10 dias no interior de câmaras hermeticamente fechadas, no escuro, a uma temperatura de aproximadamente $25^{\circ} \mathrm{C}$ (Figura 3).

Durante este período, o $\quad \mathrm{CO}_{2}$ emanado das amostras de solo é absorvido por uma solução de KOH 0,5 M e, em seguida, dosado em $\mathrm{HCl}$ 0,1 M. Utilizou-se como indicadores do ponto de viragem a fenolftaleína (1\%) e o alaranjado de metila $(0,1 \%)$. 

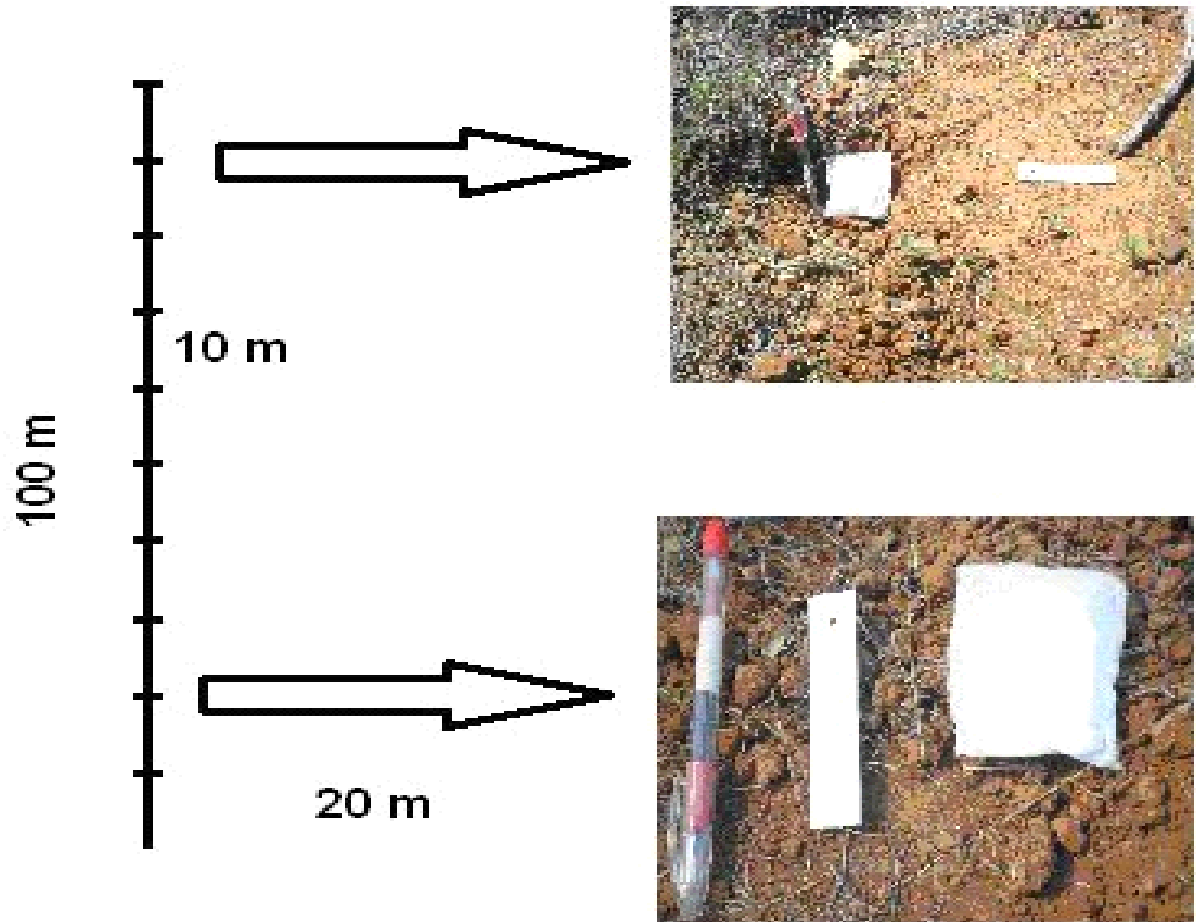

Figura 2. Disposição dos saquinhos ao longo das linhas de faixa para análise da atividade decompositora dos micro-organismos, a 20,0 $\mathrm{cm}$ de profundidade.

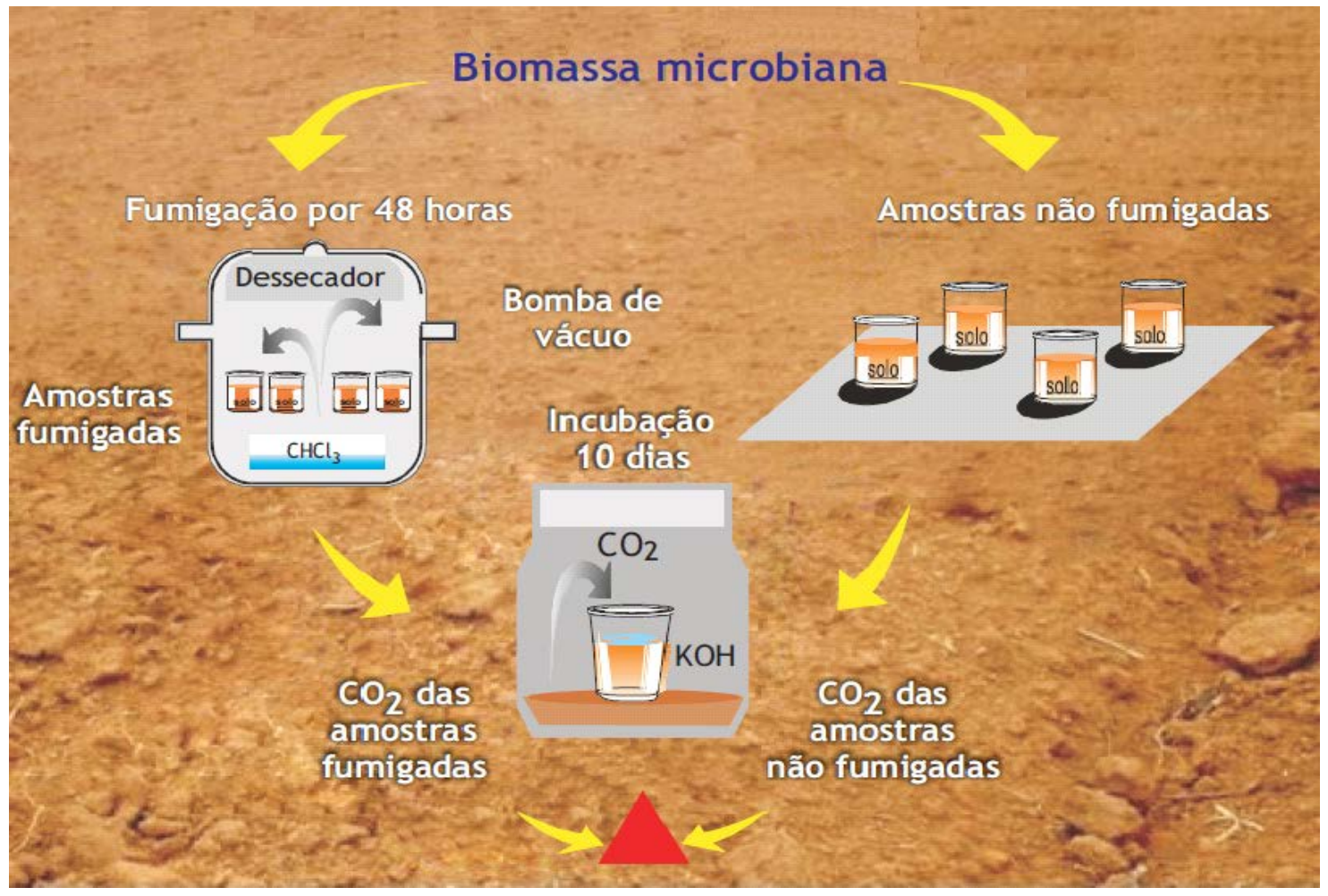

Figura 3. Esquema para a determinação da biomassa e da atividade microbiana do solo (Modificado de Reis Júnior e Mendes, 2007). 


\section{Quociente metabólico ou respiração específica da biomssa microbiana (ou $\mathrm{qCO}_{2}$ )}

Este parâmetro representa a quantidade de $\mathrm{CO}_{2}$ respirada pela $\mathrm{Bm}$ em um determinado tempo (hora), e é calculado tomando-se os valores de $\mathrm{BM}$ (em mg de C- $\mathrm{CO}_{2} .100 \mathrm{~g}^{-1}$ de solo S.E) e os de RB (em mg de C- $\mathrm{CO}_{2} .10$ dias $^{-1}$ de incubação) da amostra de solo que se deseja conhecer. 0 procedimento é:

1- Transformar em g a BM que foi calculada em mg (dividindo-se por 1000);

2- Transformar em $h$ a RB que foi obtida em 10 dias (multiplindo-se por 240), ou seja, o $\mathrm{CO}_{2}$ absorvido durante 240 horas de incubação;

3- A unidade usada é: mg de C$\mathrm{CO}_{2} \cdot \mathrm{h}^{-1} \cdot \mathrm{g}^{-1}$ de $\mathrm{BM}$, e representa a quantidade de $\mathrm{C}-\mathrm{CO}_{2}$ emitida por $1 \mathrm{~g}$ de micro-organismos durante uma hora de atividade rspiratória).

\section{$\mathrm{C}_{\text {mic }}: \mathrm{C}_{\text {org }}$ ou relacão do carbono da BM como porcentagem do carbono orgânico total do solo}

Este parâmetro representa a quantidade de carbono microbiano presente no carbono orgânico do solo, e é calculado da seguinte maneira:

1- A BM é expressa em $\mathrm{mg} / 100 \mathrm{~g}$ de solo S.E., devendo ser transformada para $\mathrm{g} / \mathrm{kg}$;

2- O carbono orgânico do solo é dado em $\mathrm{g} / \mathrm{kg}$; e

3- Como a relação é C microbiano dividido por Carbono orgânico total do solo $\left(\mathrm{C}_{\text {mic }}: \mathrm{C}_{\text {org }}\right)$, o carbono da BM deve ser, portanto, dividido pelo carbo orgânico do solo. 0 resultado é, então, um valor admensional, devendo ser multiplicado por 100 , pois é expresso em porcentagem.

\section{Delineamento estatístico para a estimativa da respiracão basal (RB) \\ Para verificar os efeitos dos níveis dos tratamentos $\mathrm{T}_{1}, \mathrm{~T}_{2}, \mathrm{~T}_{3}$ (ano de 2012) e $T_{1}, T_{2}, T_{3}$ e $T_{4}$ (ano de 2013)}

sobre a variável resposta atividade decompositora (AD) foi realizada uma análise de variância univariada considerando um delineamento inteiramente casualizado com medidas repetidas no tempo (a cada 45 dias), com 30 repetições por tratamento.

Para avaliar a adequação do modelo estatístico proposto para descrever as observações foram verificadas, além da normalidade, independência e homocedasticidade dos erros, a condição de esfericidade e uniformidade da matriz de covariância para a variável $A D$ nas 17 épocas de avaliação (coletas), de acordo com Rencher e Christensen (2012). Com este procedimento, buscou-se condições teóricas para a realização das análises estatísticas via técnicas univariadas, as quais levam em conta o princípio da parcimônia, que é a análise dos dados adotando-se um delineamento inteiramente ao acaso com parcelas subdivididas no tempo.

Para comparar as médias da variável resposta em relação aos tratamentos $\left(\mathrm{T}_{1}, \mathrm{~T}_{2}, \mathrm{~T}_{3}\right.$ e $\left.\mathrm{T}_{4}\right)$ foi utilizado o teste de Tukey ao nível de $5 \%$ de significância. E, para estudar o comportamento da variável resposta em relação às épocas de avaliação foi empregada a técnica dos polinômios ortogonais objetivando determinar $\mathrm{o}$ modelo adequado.

As análises univariadas foram conduzidas substituindo-se o estudo do comportamento da variável resposta através dos polinômios ortogonais por um teste de Tukey, comparando as médias da variável resposta relativas à estação de secas com a estação de chuvas.

\footnotetext{
Delineamento estatístico para a estimativa da biomassa microbiana (BM), respiração basal (RB), $\mathrm{qCO}_{2} \mathrm{e}$ relação $\mathrm{C}_{\text {mic }}$ : $\mathrm{C}_{\text {org }}$

O plano experimental usado para a coleta das informações relativas aos dados de biomassa microbiana (BM), atividade respiratória (AR), quociente
} 
respiratório $\left(\mathrm{qCO}_{2}\right)$ e relação $\mathrm{C}_{\text {mic }}$ : $\mathrm{C}_{\text {org }}$ foi compatível com um delineamento em blocos casualizados (ou experimento com dois fatores sem interação) em que as épocas de avaliação foram consideradas como sendo os ambientes homogêneos (ou blocos) e em cada uma delas foi instalado um conjunto completo de tratamentos. Neste contexto, as análises estatísticas das variáveis observadas neste experimento, puderam ser feitas seguindo a técnica da análise de variância - ANOVA, desde que estas variáveis atendam principalmente aos pressupostos de normalidade e homogeneidade das variâncias dentro dos tratamentos.

Como não foi possível tomar mais de uma observação por tratamento dentro de cada bloco, tornou-se inviável a aplicação de alguns testes estatísticos para avaliar a homogeneidade das variâncias. Portanto, diante desta dificuldade e na falta de uma medida mais adequada, tomou-se o coeficiente de variação do ensaio, para cada variável, como o elemento indicador da estabilidade da variância dos erros, uma vez que, de acordo com Pimentel Gomes (1985), este coeficiente mede a proporção de desvios padrão por unidade de média e é indicado para avaliar a precisão do experimento, isto é, um experimento bem conduzido em nível de campo, deve ter um C.V. abaixo de $20 \%$.

Para a verificação da normalidade dos erros foi usado o teste de Shapiro-Wilk (1965). Inicialmente, procedeu-se às análises estatísticas exploratórias dos dados originais e constatou-se que os dois pressupostos não foram simultaneamente satisfeitos. Ora o coeficiente de variação era baixo $(\mathrm{CV}<20 \%)$ e os erros não seguiam uma distribuição normal ou a precisão era baixa (CV > 20\%) e atendiam a suposição de normalidade. Com o objetivo de estabilizar a variância e normalizar os dados, buscou-se transformar os dados originais das variáveis, de modo que a transformação usada sobre os dados de cada variável fosse a mesma para os dois experimentos. Neste sentido, as transformações $\log (x+5)$, para as variáveis: $\mathrm{AD}, \mathrm{BM}$ e $\mathrm{qCO}_{2}$ e $\operatorname{arcseno}\left(\mathrm{X}^{0,25}\right)$ para a variável $\mathrm{C}_{\text {mic }}$ : $\mathrm{C}_{\text {org }}$ proporcionaram as condições para que a ANOVA fosse realizada.

Atendidas às suposições de estabilidade da variância e de normalidade dos erros, procedeu-se à análise de variância com o objetivo de testar as seguintes hipóteses:

$\mathrm{H}_{0}(\tau)$ Os tratamentos não têm efeitos sobre a variável resposta.

$\mathrm{H}_{0}(\beta)$ : As épocas de avaliação não têm efeitos sobre a variável resposta.

$\mathrm{H}_{0}(1)$ A média da variável resposta relativa aos tratamentos $\mathrm{T}_{1}$ e $\mathrm{T}_{2}$ combinados é igual à média da testemunha. [Contraste: $\left(\mathrm{T}_{1}+\mathrm{T}_{2}\right)$ vs $\mathrm{T}_{3}$, para o Experimento 1 (dados de 2012)].

$\mathrm{H}_{0}{ }^{(2)}:$ A média da variável resposta no tratamento 1 é igual à média da variável resposta no tratamento 2 (2013). (Contraste: $T_{1}$ vs $T_{2}$, para os Experimentos 1 e 2).

$\mathrm{H}_{0}(3)$ : A média da variável resposta relativa aos tratamentos $\mathrm{T}_{1}$ e $\mathrm{T}_{2}$ combinados é igual à média das testemunhas combinadas [Contraste: $\left(\mathrm{T}_{1}+\mathrm{T}_{2}\right)$ vs $\left(\mathrm{T}_{3}+\mathrm{T}_{4}\right)$ no Experimento 2],

$\mathrm{H}_{0}(4)$ : As médias da variável resposta relativas às testemunhas são iguais. (Contraste: $\mathrm{T}_{3}$ vs $\mathrm{T}_{4}$, para $\mathrm{o}$ Experimento 2).

\section{Resultados e discussão}

\section{Precipitação pluvial no município de São João do Cariri, Paraíba}

Na Tabela 1 estão representados os dados de precipitação pluvial (médias mensais máximas e mínimas) no município de São João do Cariri. Os dados nela contidos fornecem uma ideia geral da pluviosidade ocorrida naquele município nos últimos 72 anos (SUDENE, 1990). A tabela mostra que o período chuvoso (lá chamado de inverno) é muito 
curto, estendendo-se de fevereiro a maio. 0 restante do ano é marcado por intensa seca, muitas vezes estendendo-se por vários meses. A baixa disponibilidade hídrica, aliada à elevada evapotranspiração e às limitações de solos, segundo Mendes (1986), são os principais fatores responsáveis pela pobreza e pelos constantes fracassos das diversas tentativas de desenvolver técnicas que possam contribuir para a melhoria da qualidade de vida da população que vive no Semiárido.

Tabela 1. Dados de precipitação pluvial no município de São João do Cariri, Paraíba: médias mensais máximas e mínimas de 1911 a 1983.

\begin{tabular}{lcccccccccccc}
\hline & Jan & Fev & Mar & Abr & Maio & Jun & Jul & Ago & Set & Out & Nov & Dez \\
\hline № de anos & 68 & 68 & 67 & 68 & 63 & 67 & 65 & 68 & 71 & 71 & 70 & 70 \\
c/ dados & 25,8 & 54 & 90,4 & 81,2 & 48,1 & 31 & 22,8 & 6,2 & 1,8 & 5,3 & 6,2 & 12 \\
Média & 202, & 262 & 343, & 477, & 261,5 & 121 & 86 & 74,2 & 25,8 & 237 & 167 & 126, \\
Máxima & 1 & & 4 & 6 & &, 7 & & & & & & 1 \\
& 0,0 & 0,0 & 0,0 & 0,0 & 0,0 & 0,0 & 0,0 & 0,0 & 0,0 & 0,0 & 0,0 & 0,0 \\
Mínima & & &
\end{tabular}

Origem dos dados: Arquivo de microfchas da SUDENE.

Posto extinto em 1983.

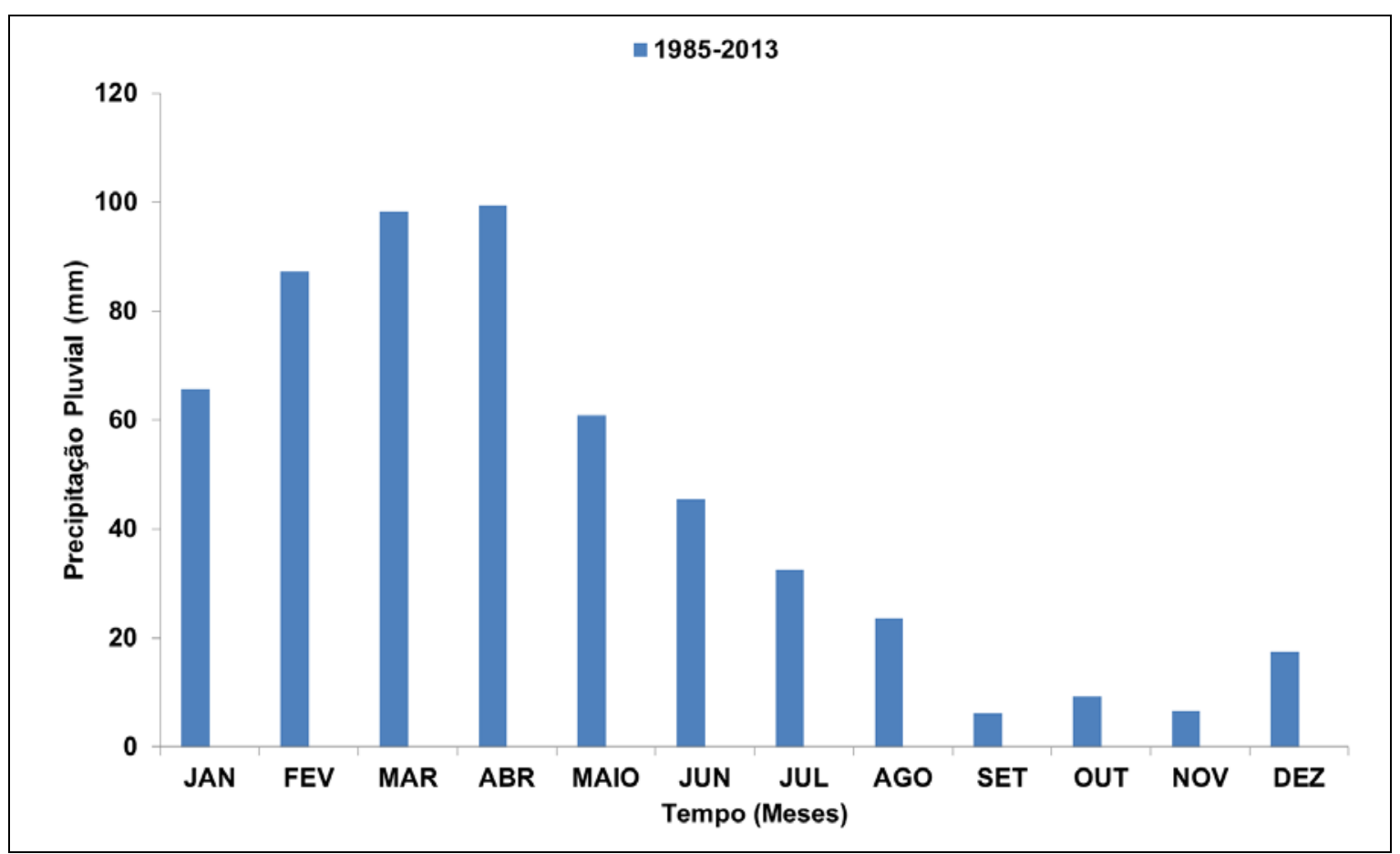

Figura 4. Médias mensais das precipitações pluviais nos últimos 28 anos (1985-2013), no Município de São João do Cariri, Paraíba. Fonte de dados: Estação Experimental de São João do Cariri, Paraíba. 
A Figura 4 mostra que as precipitações no município de São João do Cariri-PB foram de baixa intensidade, mal distribuídas durante $\mathrm{o}$ ano $\mathrm{e}$ relativamente bem distribuídas durante o período chuvoso (de janeiro a junho) e que elas se concentram nos meses de fevereiro, março e abril. Ela também revela que nos últimos 28 anos, as médias mensais nunca ultrapassaram os $100 \mathrm{~mm}$.

Por outro lado, com relação às precipitações pluviais alcançadas nos anos em que esta pesquisa foi realizada, podemos constatar que elas foram muito mal distribuídas no tempo. Observou-se que no ano de 2012 choveu muito pouco $(209,3 \mathrm{~mm})$, tendo sido os meses de janeiro $(37,9 \mathrm{~mm})$, fevereiro $(98,5 \mathrm{~mm}) \mathrm{e}$ junho $(45,2 \mathrm{~mm})$ aqueles que alcançaram as mais elevadas precipitações. De agosto a dezembro do mesmo ano, as precipitações somaram pouco mais de 2,0 mm (Figura 6).

No ano seguinte (2013), foi observado que choveu um pouco mais do que no ano anterior (268 $\mathrm{mm})$, sendo os meses de abril $(61,0 \mathrm{~mm})$, junho $(35,0$ $\mathrm{mm})$ e julho $(49,5 \mathrm{~mm})$ os que alcançaram as mais elevadas precipitações, quando deveriam ser os meses de fevereiro, março e abril, conforme podem ser observados na Figura 5, que trata do histórico de precipitações naquele município. Observou-se também que neste ano choveu mais no período seco $(163,9 \mathrm{~mm})$ do que no período chuvoso $(104,1 \mathrm{~mm})$.
Isto reafirma o fato de que uma das características mais marcantes, não só da microrregião semiárida do Cariri, mas do semiárido brasileiro como um todo, é a irregularidade das chuvas no tempo, aliada ao déficit hídrico que ocorre na maior parte do ano.

De acordo com Sampaio (2010), o regime de chuvas na região semiárida tem como características as intensas precipitações, chegando muitas vezes a superar os $100 \mathrm{~mm}$ em um único dia, e sazonalidade irregular, com o período chuvoso iniciando em diferentes meses, estendendo-se por períodos incertos e finalizando-se, também, em meses diferentes de um ano para o outro. Estas características podem ser confirmadas ao observarem a Figura 6, que trata do regime pluvial durante os anos em que esta pesquisa foi realizada.

Considerando-se, por exemplo, os meses de janeiro a junho como sendo o período chuvoso verificou-se que nestes meses o volume de água atingiu apenas $199,6 \mathrm{~mm}$ e $104,1 \mathrm{~mm}$, em 2012 e 2013, respectivamente e no período de seca (de julho a dezembro), 9,7 $\mathrm{mm}$ e 163,9 $\mathrm{mm}$, respectivamente. Estes dois conjuntos de chuvas que precipitaram nos referidos anos de estudo foram muito baixos, porém parece que foram suficientes para disparar o gatilho que impele o surgimento de pequenos pulsos de produção de fitomassa, refletidos na deposição de serapilheira nos meses seguintes de estiagem. 


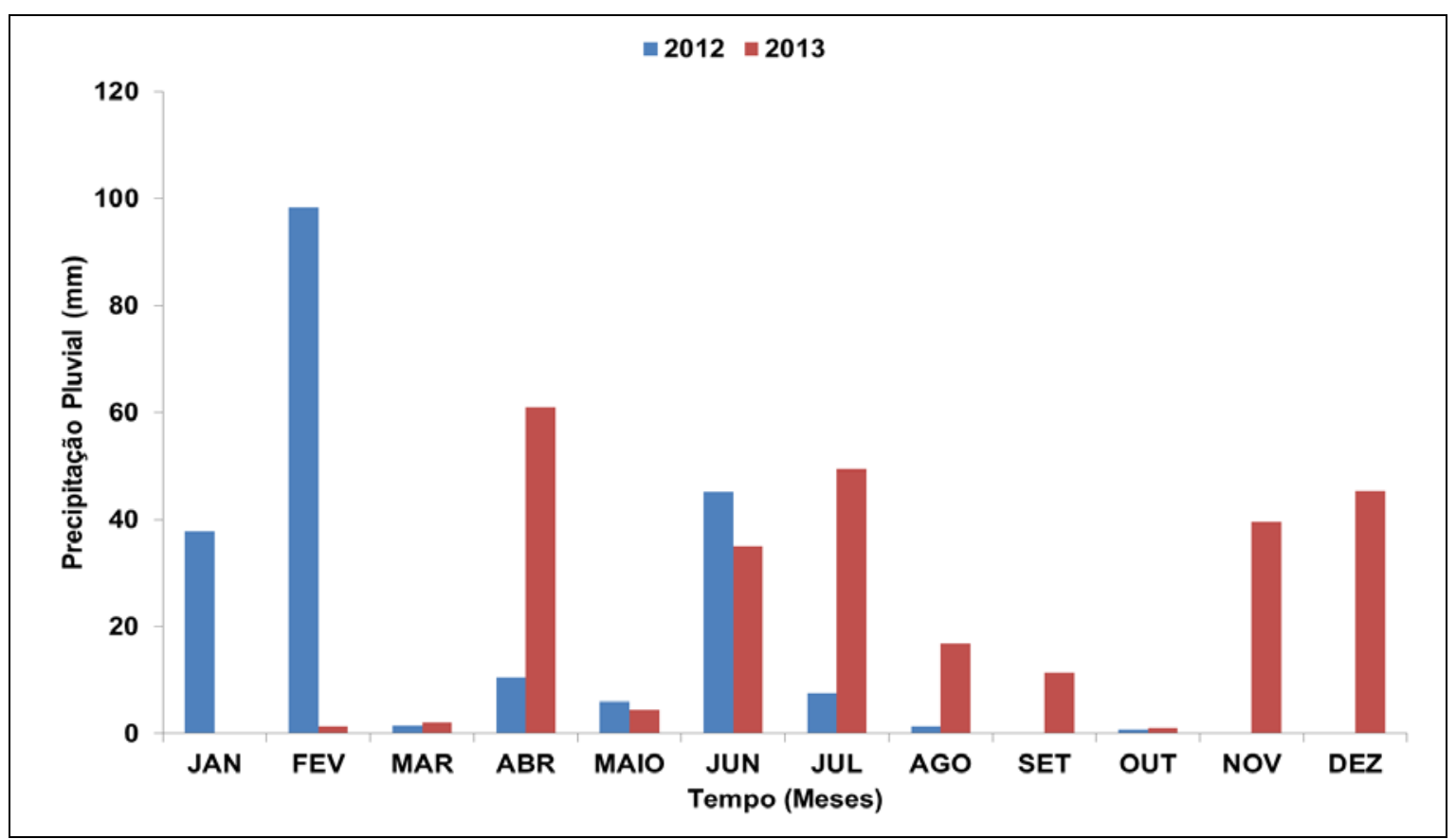

Figura 5. Precipitação pluvial mensal no Município de São João do Cariri, Paraíba, durante os anos de 2012 e 2013. Fonte de dados: Estação Experimental de São João do Cariri, Paraíba.

Temperatura e conteúdo de água no solo das áreas estudadas

Na Figura 6 são apresentados os dados de temperaturas médias mensais no município de São João do Cariri-PB, durante os anos de 2012 e 2013.

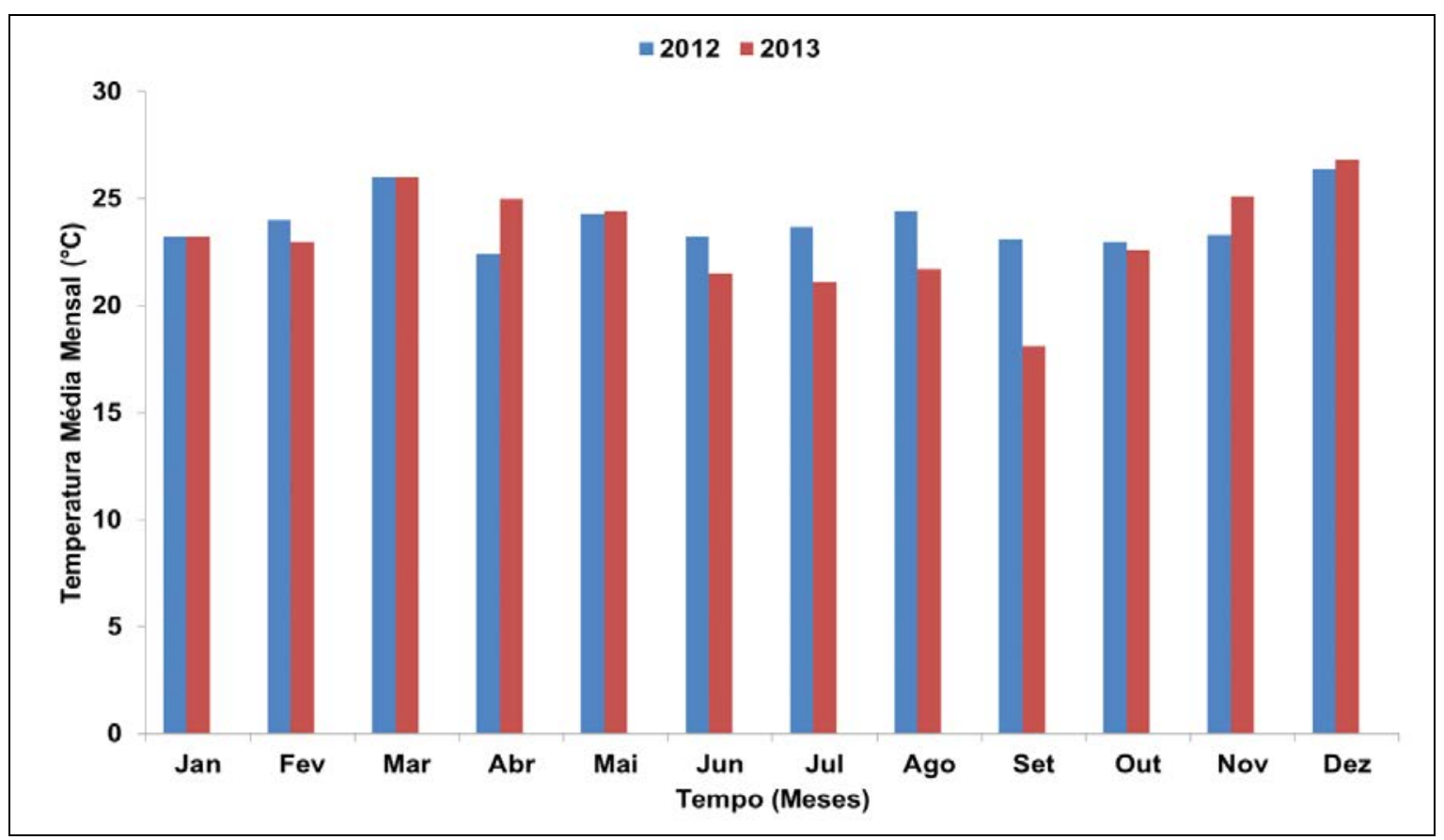

Figura 6. Temperaturas médias mensais no Município de São João do Cariri, Paraíba, durante os anos de 2012 e 2013. Fonte: Estação climatológica da Bacia Escola de São João do Cariri, Paraíba. 
As temperaturas médias mensais mais elevadas (acima de $26^{\circ} \mathrm{C}$ ) nos anos de 2012 e 2013 foram registradas nos meses de março e dezembro dos referidos anos. Observaram-se também, que no ano de 2012, estas médias estiveram acima dos $24{ }^{\circ} \mathrm{C}$, tanto no período chuvoso quanto no período de seca. Por outro lado, no ano de 2013 , as temperaturas estiveram abaixo dos $23^{\circ} \mathrm{C}$ entre os meses de junho e setembro. Estas médias de temperatura estão de acordo com aquelas registradas na maior parte das áreas de caatinga, uma vez que, segundo Mendes (1997), elas variam de $23^{\circ} \mathrm{C}$ a $27^{\circ} \mathrm{C}$ e são mais ou menos constantes em toda a região semiárida, tanto ao longo das latitudes como em relação às longitudes e durante todo o ano. De acordo com Silva et al. (1993), as poucas oscilações que ocorrem nas médias de temperatura da região semiárida são mais provocadas pela altitude (médias que variaram entre $23^{\circ} \mathrm{C}$ e $25^{\circ} \mathrm{C}$ ) do que pelas alterações na insolação.
Em suma, parece coerente afirmar que as temperaturas médias mensais registradas nos anos em que esta pesquisa foi realizada foram relativamente amenas para os padrões da região semiárida, que geralmente são mais elevadas (atingindo médias de até $27,5^{\circ} \mathrm{C}$ ).

Mesmo considerando que as temperaturas são geralmente mais baixas naqueles meses em que as precipitações são mais elevadas, ou seja, fevereiro, março e abril (Figura 5), não se observou este fenômeno durante os anos de 2012 e 2013, provavelmente por terem sido anos atípicos para a variável precipitação pluvial, que foi muito baixa.

$\mathrm{Na}$ Figura 7 é apresentado o conteúdo de água no solo das áreas estudadas, em função dos meses, nos anos de 2012 e 2013. Esses dados foram obtidos à cada 45 dias, intervalo de uma coleta para outra (épocas).

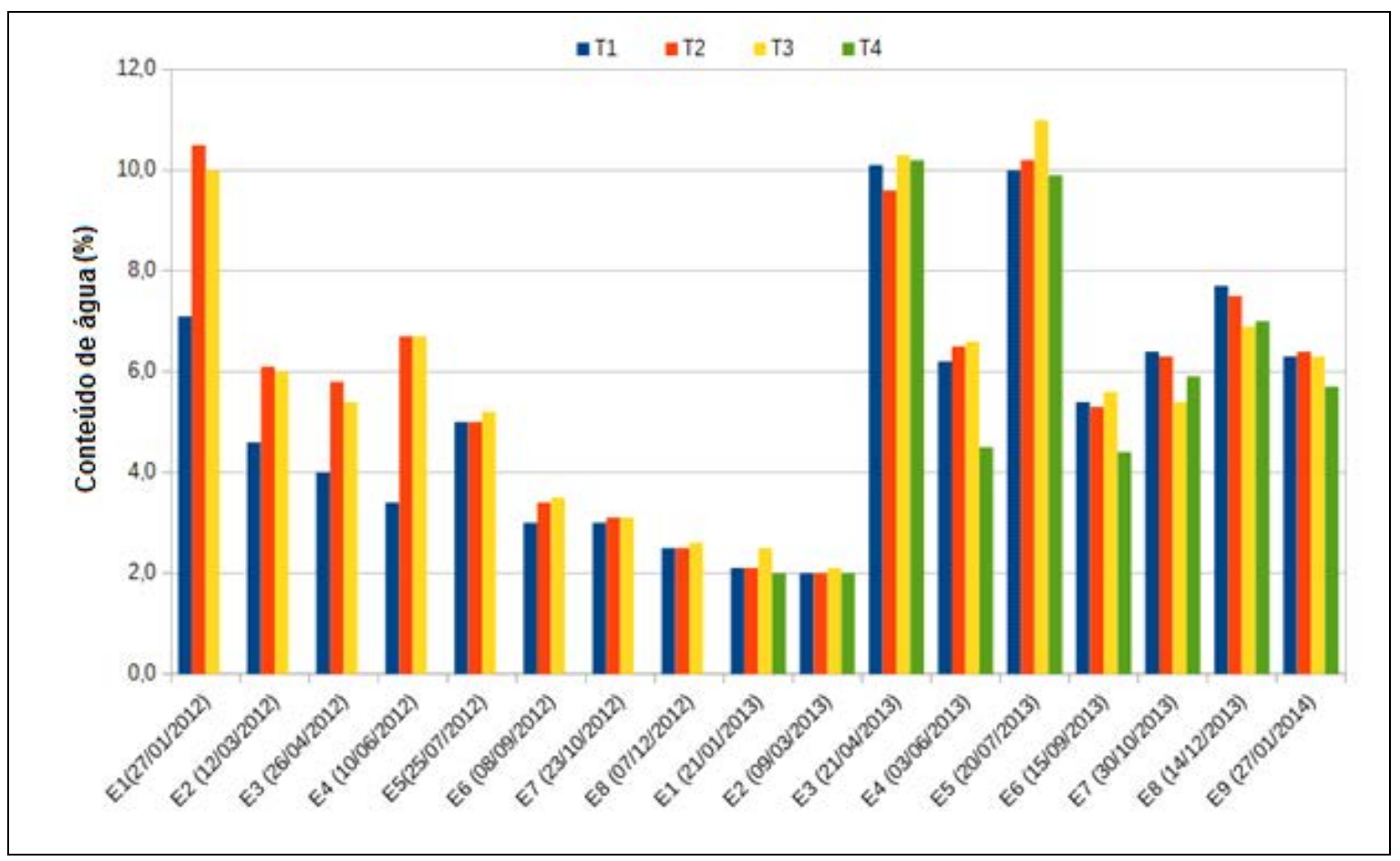

Figura 7. Conteúdo de água no solo em áreas contíguas de caatinga, no município de São João do Cariri, Paraíba. 
Verificou-se que o conteúdo de água no solo $(0-20 \mathrm{~cm})$ das áreas estudadas foi, na maioria dos meses, muito baixo, salvos aqueles meses em que ocorreram alguma precipitação pluvial (janeiro de 2012 e, em menor quantidade, abril e julho de 2013). Isto deve-se ao fato das precipitações terem sido muito baixas (Figura 5) e as temperaturas muito altas (Figura 6), favorecendo a aridez do solo, justificando assim os baixos teores de água.

Na região semiárida brasileira, a evapotranspiração potencial excede a precipitação em mais de quatro vezes. Esta condição climática frustra quaisquer chances de desenvolvimento e sustentabilidade na região, sobretudo daquelas atividades que requerem o uso direto da água, como a agricultura e a piscicultura.

Apresentando maiores chances de desenvolvimento do que a agricultura em zonas secas, a pecuária corre sérios riscos na região semiárida brasileira, principalmente enquanto não se dispor de informações sobre a capacidade de suporte das áreas aonde ela vem sendo praticada. Segundo Sampaio (2010), onde a taxa de lotação foi excedida, a degradação ambiental esteve quase sempre presente, refletida na depauperação da vegetação arbustiva e herbácea pelo gado, além da eliminação de plântulas e ramos das espécies arbóreas. Ainda de acordo com o referido autor, os efeitos desta eliminação sistemática na composição florística das pastagens nativas da Caatinga são ainda desconhecidos.

Ao analisarem-se os dados de temperaturas médias mensais dos anos de 2012 e 2013 observou-se que estas variaram muito pouco tanto de um ano para o outro, quanto de um mês para outro. Observou-se ainda que estas temperaturas são relativamente amenas para os padrões da região semiárida, que geralmente são mais elevadas.
Mesmo considerando que as temperaturas sejam geralmente mais baixas naqueles meses em que as precipitações são mais elevadas (período chuvoso), ou seja, fevereiro, março e abril, não se observou este fato durante os anos de 2012 e 2013, provavelmente por terem sido anos atípicos, ou seja, de precipitações muito baixas (Figura 6).

\section{fertilidade \\ Análise de solo: química e Os solos predominantes na} referida Bacia são os LUVISSOLOS Crômicos Vérticos, os VERTISSOLOS e os NEOSSOLOS líticos, de acordo com Chaves et al. (2000). São solos rasos com presença de afloramentos rochosos. São relativamente planos, suavemente ondulados, de acordo com os referidos autores. As análises granulométricas efetuadas por Parente (2009) e Lima (2014), revelaram que o solo das áreas I, II e III são de texturas franco arenosa. Como estas áreas são contíguas, é bem possível que o solo da área IV também apresente a mesma textura.

Na Tabela 2 são apresentados os resultados da análise química $\mathrm{e}$ fertilidade dos solos das áreas estudadas. As amostras de solo foram coletadas do horizonte mineral na profundidade de 0 $20 \mathrm{~cm}$ em quinze parcelas alternadas.

Com relação ao $\mathrm{pH}$ do solo das áreas estudadas e considerando a escala de $\mathrm{pH}$ para acidez do solo (elevada, média, fraca, neutra, alcalinidade fraca, alcalinidade elevada) e seus respectivos valores $(\leq 5,0$; de 5,0 a 5,9 ; de 6,0 a 6,9 ; 7,$0 ;$ de 7,1 a 7,$8 ; \geq 7,8$ ), conclui-se que, de modo geral, a acisez variou de média a fraca, permitindo inferir que os solos de tais áreas não apresentam problemas relacionados à deficiência de fósforo, cálcio, magnésio, potássio, micronutrientes, saturação por bases e CTC. Segundo Tomé Jr. (1997), os solos só são considerados muito ácidos quando o pH em água for menor que 5,0. 
Tabela 2. Química e fertilidade dos solos provenientes de quatro áreas de caatinga do município de São João do Cariri, Paraíba.

\begin{tabular}{|c|c|c|c|c|}
\hline & Área I & Área II & Área III & Área IV \\
\hline $\mathrm{pH}\left(\mathrm{H}_{2} \mathrm{O}\right) 1: 2: 5$ & 6,03 & 5,88 & 6,42 & 5,55 \\
\hline P mg.dm ${ }^{-3}$ & 35,93 & 7,88 & 66,22 & 7,69 \\
\hline $\mathrm{K} \mathrm{mg.dm}{ }^{-3}$ & 118,66 & 98,40 & 147,09 & 98,40 \\
\hline $\mathrm{Na}$ cmolc.dm ${ }^{-3}$ & 1,45 & 0,50 & 0,07 & 0,86 \\
\hline $\mathrm{H}^{++} \mathrm{Al}^{+3} \mathrm{cmolc}^{-\mathrm{dm}^{-3}}$ & 1,49 & 1,40 & 1,40 & 1,57 \\
\hline $\mathrm{Al}^{+3} \mathrm{cmolc} \mathrm{dm}^{-3}$ & 0,10 & 0,10 & 0,10 & 0,10 \\
\hline $\mathrm{Ca}^{++}{\text {cmolc. } \mathrm{dm}^{-3}}^{-3}$ & 4,70 & 5,25 & 8,40 & 2,70 \\
\hline $\mathrm{Mg}^{++}$cmolc. $\mathrm{dm}^{-3}$ & 3,20 & 3,70 & 5,80 & 3,45 \\
\hline SB cmolc. dm ${ }^{-3}$ & 9,65 & 9,70 & 14,65 & 7,26 \\
\hline CTC cmolc. $\mathrm{dm}^{-3}$ & 11,14 & 11,10 & 16,05 & 8,83 \\
\hline V\% & 86,62 & 87,39 & 91,28 & 82,22 \\
\hline $\mathrm{m} \%$ & 1,03 & 1,02 & 0,68 & 1,36 \\
\hline M.0. g.kg-1 & 4,68 & 10,64 & 7,60 & 6,90 \\
\hline
\end{tabular}

Análise realizada no Laboratório de Solos, do Centro de Ciências Agrárias, da Universidade Federal da Paraíba - Campus II, Areia. Área I - 10 animais; área II - 5 animais; Áreas III e IV - Sem animais.

Segundo Effgen et al. (2008), solos com pH acima de 5,5, como os solos aqui analisados, a maior parte do alumínio torna-se precipitado e, por conseguinte, não provoca toxicidade às plantas.

0 solo do tratamento $\mathrm{T}_{3}$ apresentou o $\mathrm{pH}$ mais próximo da neutralidade $(6,42)$, comparativamente aos outros analisados.

0 solo do tratamento $T_{3}$ (sem animais) apresentou o mais elevado teor de fósforo, seguido pelo solo do tratamento $\mathrm{T}_{1}$, onde encontra-se a maior densidade de caprinos. Ambos apresentaram teores de fósforo disponíveis altos (teor acima de 30,0 mg. $\mathrm{dm}^{-3}$ ). Para o solo dos tratamentos $\mathrm{T}_{2}$ e $\mathrm{T}_{4}$ os teores foram considerados baixos, pois encontram-se abaixo de 10,0 mg.dm3. Era esperado que o solo de $\mathrm{T}_{1}$ fosse $o$ que apresentasse os maiores teores de fósforo, não pela maior densidade de caprinos, mas sim, por esta área ter apresentado maior densidade de plantas (1.375 ind.ha-1) e maior produção média anual de serapilheira $\left(1.971 \mathrm{~kg}^{-h^{-1}}{ }^{-}\right.$.ano1). Por outro lado, ao observarem-se os teores de matéria orgânica na Tabela acima, consta-se que o solo do tratamento $\mathrm{T}_{2}$ apresentou o maior valor
$(10,64$ g.kg-1) e, por conseguinte, esperava-se que ele detivesse também o maior valor de fósforo.

Resumidamente, os tores de fósforo do solo aqui obtidos em $\mathrm{T}_{3}>\mathrm{T}_{1}>$ $\mathrm{T}_{2}>\mathrm{T}_{4}$, foram respectivamente $66,22>$ $35,93>7,88>7,69 \mathrm{mg}^{-} \mathrm{dm}^{-3}$. Lima (2014), estudando três das quatro áreas aqui estudadas, obteve maior teor de fósforo também no solo da área III $(6,87$ mg. $\left.\mathrm{dm}^{-3}\right)$, seguido pelo solo das áreas II (6,41 mg.dm-3) e I (5,83 mg.dm-3), porém diferindo muito quanto aos valores aqui obtidos nas áreas II e III, que foram 5 e 10 vezes inferiores, respectivamente. Da mesma forma, Éder-Silva (2009), também obteve valores ainda mais baixos no solo das áreas I e II, que foram 1,65 e 1,71 mg.dm-3, respectivamente. Esta falta de congruência de valores leva a crer que estas análises não merecem confiança, uma vez que todas elas foram efetuadas no mesmo laboratório. É conhecido o fato de que boa parte dos equipamentos laboratoriais brasileiros é obsoleta e cuja descartabilidade já deveria ter acontecido há tempos frente às novas tecnologias existentes e cuja obsolescência também já foi programada. De acordo com Menezes et al. (2012), a concentração média de fósforo 
em solos de Caatinga, na camada superficial (0-20 cm), é de $196 \mathrm{mg}$. kg-1, e a de $\mathrm{C}$ é $9.3 \mathrm{~g}$. $\mathrm{kg}^{-1}$, correspondendo a estoques médios em torno de $23 \mathrm{Mg}$. ha-1 de carbono.

cristalino semiárido apresentam deficiência de fósforo, mas não de potássio, cálcio ou magnésio (SAMPAIO, 2010).

Com relação ao potássio trocável, de forma genérica, seus teores podem ser considerados médios para o solo das áreas I, II e IV (entre 40 e 120 mg.dm ${ }^{-3}$ ). $\mathrm{O}$ solo da área III apresenta teor de $\mathrm{K}$ trocável considerado alto (maior que 120 mg.dm ${ }^{-3}$ ).

Estes valores são considerados muito superiores aos obtidos por Lima (2014), que foram 0,38; 0,46 e 0,40 $\mathrm{mg} \mathrm{dm}^{-3}$ nas áreas I, II e III, respectivamente, e por Éder-Silva (2009), nas áreas I e II, que foram 0,19 e $0,26 \mathrm{mg} \cdot \mathrm{dm}^{-3}$, respectivamente.

A interpretação do sódio trocável e a saturação por sódio $\left(^{*}\right)$ é de interesse principalmente para a classificação do solo. Assim, solos que apresentam caráter sódico são aqueles que apresentam porcentagem de sódio trocável $>15 \%$ e os de caráter solódico, os que apresentam porcentagem de sódio trocável variando entre 6 e $15 \%$. Assim, os solos dos tratamentos $\mathrm{T}_{1}$ e $\mathrm{T}_{4}$ são de caráter solódico. Os teores dos tratamentos $\mathrm{T}_{2}$ e $\mathrm{T}_{3}$ não classificam os solos nem como solódicos ou sódicos, pois a saturação por sódio trocável é inferior a $6 \%$.

Sódio trocável/Saturação por sódio: Área 1 - 1,45 cmolc. dm $^{-3} * 13 \%$; Área 2 - 0,50 cmolc.dm ${ }^{3} . * 4,5 \%$; Área 3 0,07 cmolc.dm $^{-3} .0,44 \%$; Área 4 - 0,86 cmolc.dm ${ }^{-3} .9,74 \%$.

Para apresentar caráter sódico, o PST deve ser maior ou igual a $15 \%$.

Foi observado que o maior teor de sódio registrado ocorreu no $\mathrm{T}_{1}$, onde se obteve o menor teor de matéria orgânica e o maior de serapilheira. Este material tem decomposição acelerada no período chuvoso e, consequentemente, a mineralização também, justificando este resultado.

Os teores de cálcio e magnésio para os tratamentos são considerados altos, exceto para o tratamento $\mathrm{T}_{4}$, com relação ao teor de cálcio trocável, que apresentou valor entre 2 e 4 cmolc. dm $^{-3}$. As escalas para o cálcio e o magnésio são apresentadas a seguir:

\section{Cálcio \\ Teor alto - > 4 cmolc. $\mathrm{dm}^{-3}$; \\ Teor médio - 2 a 4 cmolc. $\mathrm{dm}^{-3}$; \\ Teor baixo $-<2$ cmolc. $\mathrm{dm}^{-3}$}

\section{Magnésio}

Teor alto - >0,8 cmolc. $\mathrm{dm}^{-3}$; Teor médio - 0,4 a 0,8 $\mathrm{cmolc}^{-\mathrm{dm}^{-3}}{ }^{3}$; Teor baixo - $<0,4 \mathrm{cmolc} \mathrm{dm}^{-3}$

Os maiores teores de $\mathrm{Ca}$ e $\mathrm{Mg}$ foram registrados no solo da área III (sem caprinos), onde foi registrada a menor densidade de plantas e de serapilheira (embora sem coprovacão estatística), comparativamente às áreas I (10 animais) e II (5 animais). Isto deve ter ocorrido principalmente devida à importação desses elementos provenientes das áreas I e II, uma vez que, por serem áreas contíguas, a área III encontrava-se na extremidade mais baixa de um declive. As chuvas torrenciais que ali ocorrem, embora raras, por ação cinética pôde, ao longo dos tempos, ter arrastado parte desses elementos para os declives mais suaves, conferindo maiores teores desses elementos no solo dessa área. A hipótese de Lima (2014), que também obteve maiores teores desses elementos na mesma área, não deve ser desconsiderada nem também levada muito à sério. Segundo ele, a serapilheira ali encontrada, livre da ação consumidora dos caprinos, permaneceu no solo e foi totalmente mineralizada. Esta declaração não foi aqui considerada um forte argumento, uma vez que, a serapilheira das áreas II e III também permaneceram no local, elas apenas 
foram ingeridas e devolvidas ao biossistema após a digestão. Como os caprinos ali manejados não são exportados (juntamente com esses nutrientes em seus tecidos), estes acabam sendo, sedo ou tarde, devolvidos ao ambiente. Estes animais, portanto, até ajudam a acelerar a decomposição da serapilheira ao agirem como decompositores (mas não mineralizadores) dessa necromassa. Por outro lado, sabe-se também que os ecossistemas se opõem à segunda Lei da Termodinâmica e que eles são considerados sistemas abertos para a energia e fechados para a matéria (ODUM, 1988; BEGON et al., 1990), ou seja, a energia é sempre perdida à cada transferência de um nível trófico para o outro, porém a matéria e os nutrientes nela contida, tendem a ficarem presos dentro dos ecossistemas, principalmente quando estes forem bem equilibrados. Como se trata de um agroecossistema e não de um ecossistema, a matéria e os nutrientes nele contidos tendem a se perderem mais facilmente em virtude de sua deficiência em mecanismos de controle, perdidos pela degradação imputada.

Os teores de alumínio trocáveis e valores de $\mathrm{m} \%$ foram considerados baixos para as quatro áreas e, portanto, não são prejudiciais ao desenvolvimento das plantas. A escala para o alumínio e para acidez potencial são:

\section{Alumínio \\ Teor alto - > 1,5 cmolc.dm-3. \\ Teor médio - 0,5 a 1,5 cmolc. dm-3.

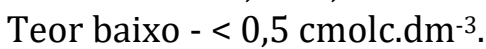

\section{Acidez Potencial ( $\mathrm{H}+\mathrm{Al})$}

Área 1 - 1,49 cmolc.dm-3 ${ }^{-3}$. Área 2 - 1,40 cmolc.dm ${ }^{-3}$. Área 3 - 1,40 cmolc.dm ${ }^{-3}$. Área 4 - 1,57 cmolc.dm ${ }^{-3}$.

Não há classificação para os teores de $\mathrm{H}+\mathrm{Al}$, pois o objetivo principal dessa determinação é o cálculo da capacidade de troca de cátions - CTC.
Com relação à saturação por bases, os solos das quatro áreas podem ser classificados como "Solos Eutróficos", pois apresentam $\mathrm{V} \%$ maior ou igual a $50 \%$. A escala é:

Solos eutróficos (férteis) - V\% maior ou igual a $50 \%$.

Solos distróficos (pouco férteis) - $V \%$ menor que $50 \%$.

Os solos das quatro áreas apresentam uma elevada soma de bases (teores de $\mathrm{Ca}, \mathrm{Mg}, \mathrm{K}$ e $\mathrm{Na}$ elevados), fato este observado nos valores da CTC calculada e V\% observados.

Isso corresponde a dizer que tais solos apresentam uma elevada quantidade de cargas negativas ocupadas pelos cátions básicos trocáveis $(\mathrm{Ca}, \mathrm{Mg} \mathrm{e}$ $\mathrm{K})$.

$$
\begin{aligned}
& \mathrm{SB}=\mathrm{Ca}+\mathrm{Mg}+\mathrm{K}+\mathrm{Na} \\
& \mathrm{CTC}=\mathrm{SB}+(\mathrm{H}+\mathrm{Al})
\end{aligned}
$$

Todas as áreas apresentam baixos teores de matéria orgânica, ou seja, teores menores que 15 g. $\mathrm{dm}^{-3}$. Os teores seriam considerados altos se fossem maiores que $50 \mathrm{~g} . \mathrm{dm}^{-3}$.

Os baixos teores de matéria orgânica do solo em regiões semiáridas é o resultado do balanço entre os processos que adicionam material orgânico, como a produção de serapilheira e os processos que removem (exportação), como a erosão e o consumo pelos rebanhos (com vistas ao abate e comércio).

De acordo com Martins et al. (2010) a matéria orgânica é, não só um parâmetro de fácil avaliação das condições do solo, mas também uma ferramenta de fácil aquisição e capaz de indicar estágios de degradação. Frente ao crescente número de áreas em processo de degradação oriundo de causas naturais ou antropogênicas, o uso desse parâmetro como ferramenta sinalizadora de mudanças é imprescindível. Ainda de acordo com os referidos autores, dentre os parâmetros passíveis de avaliação, a 
matéria orgânica do solo e a serapilheira têm recebido considerável crédito.

Alguns autores, como Doran e Parkin (1994) também acreditam que a matéria orgânica apresenta potencial para ser utilizada como atributo-chave da qualidade do solo, pois, além de ser altamente sensível às diversas formas de manejo do solo, ela é ainda um reservatório temporário de nutrientes para às plantas, sendo capaz também de influenciar a infiltração, retenção de água e susceptibilidade à erosão.

Com relação ao nitrogênio, elemento químico aqui não analisado, segundo Salcedo e Sampaio (2008), quase todos os solos do Semiárido brasileiro apresentam deficiência quanto a este nutriente. Segundo os referidos autores, os baixos teores de nitrogênio registrados nesta região encontram-se acumulados na matéria orgânica. Esta, por sua vez, tem produção vegetal limitada e mineralização acelerada no período chuvoso.

A classificação textural do solo das áreas estudadas foi, segundo Lima (2014), Éder-Silva (2009) e Parente (2009), é Franco arenosa, e a densidade desses mesmos solos 1,52 g. m-3 e 1,51 g. $\mathrm{m}^{-3}$, nas áreas I e II (com 10 animais e 5 animais, respectivamente) e $1,41 \mathrm{~g} . \mathrm{m}^{-3}$ na área III (sem animais). Esta gradação densitométrica foi, segundo Lima (2014), uma consequência do pisoteio dos animais ali manejados (área I e II) e da ausência destes (área III, onde o solo apresentou menor densidade).

Como análise geral pode-se aqui inferir que o solo da área III (sem animais) apresentou o $\mathrm{pH}$ mais próximo da neutralidade, os maiores teores dos macronutrientes ( $\mathrm{P}, \mathrm{K}, \mathrm{Ca}$ e $\mathrm{Mg}$ ) e valores de CTC, V\% e SB do que o solo das áreas I e II (com caprinos) e IV (sem caprinos), sugerindo que este solo apresenta as melhores condições ao desenvolvimento de pastagens introduzidas ou de reabilitação da vegetação nativa.

\section{Atividade decompositora}

As análises estatísticas realizadas sobre a variável resposta atividade decompositora (AD) ou decomposição de celulose (DC), nos anos 2012 e 2013, consideraram que as medidas foram obtidas de um experimento com um fator (One-Way) em quatro níveis $\left(\mathrm{T}_{1}, \mathrm{~T}_{2}, \mathrm{~T}_{3} \mathrm{e}\right.$ $\mathrm{T}_{4}$ ) com as medidas repetidas no tempo (coletas). Isto é, a decomposição de celulose foi avaliada a cada 45 dias nas mesmas unidades experimentais. Este esquema de obtenção de informação sobre a variável resposta decomposição de celulose permitiu que as análises estatísticas fossem realizadas multivariadamente, considerando que as medidas da decomposição de celulose nas coletas subsequentes fossem dependentes daquelas observadas nas coletas anteriores.

Segundo Rencher e Christensen (2012), se a variável em estudo atende às suposições de normalidade, independência e circularidade da matriz de covariância entre as coletas, as análises poderão ser realizadas considerando-se que os dados sobre a decomposição de celulose foram obtidos de um delineamento inteiramente ao acaso com parcelas subdivididas (Splitplot) no tempo, facilitando sobremaneira a interpretação dos resultados das análises estatísticas e evidenciando-se os achados na pesquisa.

As análises preliminares realizadas, com o objetivo de checar as suposições acerca do modelo estatístico proposto para descrever as observações confirmaram através dos coeficientes de variação estimados, que os valores da decomposição de celulose variaram muito, comprometendo a precisão do experimento em nível de campo (ver coluna 2 da Tabela 3). Uma outra interpretação para essa acentuada variação das taxas de decomposição de celulose deve ser considerada. Sabe-se que algumas amostras podem ter ficado 
em contato com a rizosfera, com microbiota mais abundante, que pode ter contribuído para uma maior decomposição celulolítica, outras, em locais extremamente desprovidos de vegetação ou de cobertura morta, com baixíssima microbiota, pode ter contribuído para uma menor ou nenhuma decomposição de celulose.

Mesmo sendo coerente admitir que os resultados das amostras na mesma coleta sejam independentes e que de uma coleta para outra sejam dependentes, as condições de normalidade e homogeneidade das variâncias nos tratamentos, em cada coleta, não se verificaram, uma vez que ao conduzir o teste de Shapiro-Wilk (1965), para normalidade e os testes de Levene (1960) e Bartlett (1937) para homogeneidade das variâncias, constatou-se que existem fortes evidências de que estas hipóteses são rejeitadas (ver colunas 3, 4 e 5, da Tabela 3).

Diante de tal situação, buscou-se fazer uma transformação nos dados com o objetivo de aproximar da distribuição normal e estabilizar a variância. Contudo, ao utilizarem as técnicas de transformação de potência sugerida por Box e Cox (1964) através do programa SAS versão 9.4 (2014), constatou-se que esta era inviável para quase a totalidade dos dados considerados coleta-a-coleta.

Frente à impossibilidade de analisar os dados de acordo como foi planejado no projeto original, buscou-se num primeiro momento, explorar os resultados através das técnicas descritivas e em seguida utilizou-se as técnicas não-paramétricas com 0 objetivo de inferir alguns resultados.

Os resultados das análises descritivas basearam-se apenas nos valores médios da decomposição de celulose relativos aos tratamentos, às coletas e à interação Tratamento $v s$ Coleta. Tais resultados encontram-se apresentados na Tabela 3.

Conforme pode ser vista na última linha da Tabela 3, a decomposição de celulose média relativa aos tratamentos independentemente das coletas, não apresentou um comportamento sistemático como $\mathrm{o}$ esperado (que $\mathrm{T}_{1}$ e $\mathrm{T}_{2}$ apresentassem menores taxas de decomposição de celulose média do que as testemunhas $\mathrm{T}_{3}$ e $\mathrm{T}_{4}$ ). Mesmo assim, esta aparente superioridade das taxa de decomposição observadas nos tratamento $\mathrm{T}_{1}$ e $\mathrm{T}_{2}$ não foi comprovada estatisticamente.

Observando-se os valores médios da decomposição de celulose em relação às coletas nos anos estudados, apresentados na última coluna da Tabela 3 , constatou-se que parece razoável dizer que há evidência de que pelo menos duas médias difiram entre si, sendo esta conclusão puramente descritiva.

Visto que a decomposição média de celulose observada em relação aos tratamentos se comportou diferentemente de uma coleta para outra e que as médias da decomposição de celulose em relação às coletas dentro de cada tratamento comportaram-se de modo diferente, isto indica que provavelmente exista interação entre os tratamentos e as coletas, ou seja, a decomposição de celulose em relação aos tratamentos se comportou de uma forma em uma coleta e de outra forma em outra coleta, ou que a decomposição de celulose em relação às coletas se comportou de um modo dentro de um tratamento e de outro modo dentro do outro tratamento. 
Tabela 3. Valores obtidos dos coeficientes de variação (C.V), da estatística de Shapiro-Wilk (W) para o teste de normalidade, das estatísticas de Levene e Bartlett ( $F$ e $X^{2}$ ) para o teste de homogeneidade das variâncias e das médias (repetições) da decomposição de celulose relativas aos tratamentos, em cada coleta nos anos de 2012 e 2013.

\begin{tabular}{|c|c|c|c|c|c|c|c|c|c|}
\hline \multirow[t]{2}{*}{ Coleta } & \multirow[t]{2}{*}{ C.V. (\%) } & \multirow{2}{*}{$\begin{array}{c}\text { Valores obtidos } \\
\text { para a Estatística } \\
\text { de Shapiro-Wilk } \\
\text { (W) }\end{array}$} & \multicolumn{2}{|c|}{$\begin{array}{c}\text { Valores obtidos para as } \\
\text { estatisticas de: Levene } \\
\text { e Bartlett }\end{array}$} & \multicolumn{5}{|c|}{$\begin{array}{l}\text { Valores médios (repetiçōes) da decomposição de celulose por } \\
\text { tratamento e coleta }(\mathrm{g} / 45 \text { dias) }\end{array}$} \\
\hline & & & $\mathbf{F}$ & $\mathrm{X}^{2}$ & $\mathrm{~T}_{1}$ (R1) & $\mathrm{T}_{2}(\mathrm{R} 2)$ & $\mathrm{T}_{3}(\mathrm{R} 3)$ & $T_{4}$ (R4) & Geral \\
\hline$E_{1}(27 / 01 / 12)$ & 78,3 & $0,934^{* *}$ & $4,34^{*}$ & $6,82^{*}$ & $0,483(29)$ & $0,266(27)$ & $0,255(27)$ & - & 0,338 \\
\hline$E_{2}(12 / 03 / 12)$ & 90,8 & $0,967^{*}$ & 2,78 & $8,18^{*}$ & $0,261(29)$ & $0,160(28)$ & $0,139(28)$ & . & 0,188 \\
\hline$E_{3}(26 / 04 / 12)$ & 250,6 & $0,461^{4 *}$ & 1,95 & $75,20^{* 4}$ & $0,008(30)$ & $0,003(30)$ & $0,008(30)$ & - & 0,007 \\
\hline$E_{4}(10 / 06 / 12)$ & 49,2 & $0,967^{* *}$ & $3,91^{*}$ & 4,55 & $0.582(30)$ & $0,465(27)$ & $0,360(30)$ & - & 0,469 \\
\hline$E_{5}(25 / 07 / 12)$ & 387,0 & $0,238^{* *}$ & 1,09 & $185,70^{* 4}$ & $0,014(30)$ & $0,003(30)$ & $0,010(30)$ & - & 0,009 \\
\hline$E_{6}(08 / 09 / 12)$ & 69,9 & $0,968^{+}$ & 1,76 & 2,07 & $0,010\{29\}$ & $0,010(30)$ & $0,014(30)$ &. & 0,012 \\
\hline $\mathbf{E}_{7}(23 / 10 / 12)$ & 111.1 & $0.919^{* *}$ & $5,09^{* *}$ & $7.76^{*}$ & $0.005(29)$ & $0.005(24)$ & $0.013(29)$ & - & 0,008 \\
\hline$E_{8}(07 / 12 / 12)$ & 130,0 & $0,857^{* *}$ & $4,60^{*}$ & $11,90^{* *}$ & $0,020(27)$ & $0,019(28)$ & $0,079(28)$ & - & 0,039 \\
\hline$E_{1}(21 / 01 / 13)$ & 194,5 & $0,662^{* *}$ & $8,66^{* *}$ & $247,80^{* 4}$ & $0,004(12)$ & $0,008(22)$ & $0,016(29)$ & $0,140\{28)$ & 0,050 \\
\hline $\mathbf{E}_{2}(09 / 03 / 13)$ & 303,3 & $0,460^{* *}$ & 2,10 & $266,30^{* 4}$ & $0,002(20)$ & $0,003(16)$ & $0,003(30)$ & $0,037\{27\}$ & 0,013 \\
\hline$E_{3}(21 / 04 / 13)$ & 76,8 & $0,950^{* *}$ & $9,83^{* *}$ & 18,34 ** & $0,465(28)$ & $0,212(18)$ & $0,240(30)$ & $0,249(30)$ & 0,297 \\
\hline $\mathbf{E}_{4}(03 / 06 / 13)$ & 95,4 & $0,918^{* *}$ & 1,96 & $8,49^{*}$ & $0,359(30)$ & $0,139(16)$ & $0,158(30)$ & $0,166(30)$ & 0,214 \\
\hline$E_{5}(20 / 07 / 13)$ & 66,6 & $0,879^{* 4}$ & 2,08 & $10,60^{*}$ & $0,201(27)$ & $0,136(23)$ & $0,084(30)$ & $0,070\{30\}$ & 0,120 \\
\hline $\mathbf{E}_{6}(15 / 09 / 13)$ & 129.8 & $0,885^{* *}$ & $3.56^{*}$ & $17,76^{* *}$ & $0,004(27)$ & $0,003(29)$ & $0,009(29)$ & $0.007\{27\}$ & 0,006 \\
\hline$E_{7}(30 / 10 / 13)$ & 80,5 & $0,964^{* *}$ & $8,72^{* *}$ & $14,96^{* *}$ & $0,465(30)$ & $0,359(27)$ & $0,254(30)$ & $0,133(28)$ & 0,304 \\
\hline$E_{8}(14 / 12 / 13)$ & 179,1 & $0,738^{* *}$ & $3,45^{*}$ & $79,93^{* *}$ & $0,153(29)$ & $0,096(27)$ & $0,019(2 B)$ & $0,025\{27)$ & 0,074 \\
\hline$E_{9}(27 / 01 / 14)$ & 91,7 & $0,922^{* *}$ & $2,69^{*}$ & $9,55^{*}$ & $0,321\{28\}$ & $0,207(28)$ & $0,175(26)$ & $0,120\{26]$ & 0,208 \\
\hline Média & - & - & - & - & $0,210(464)$ & $0,123(430)$ & $0,107(494)$ & $0,107(253)$ & - \\
\hline
\end{tabular}

$\mathbf{E}_{1}, \mathbf{E}_{2}, \mathbf{E}_{3}, \ldots \mathbf{E}_{\mathbf{9}}$ - Épocas de coleta nos anos de 2012 e 2013. ( $\left.{ }^{* *}\right)$ Hipótese nula $\left(\mathrm{H}_{0}\right)$ rejeitada ao nível de $1 \%$ de significância; $\left({ }^{*}\right)$ Hipótese nula rejeitada ao nível de $5 \%$ de significância. Hipóteses nulas e hipóteses alternativas contrastadas: $\mathrm{H}_{0}$ : os erros seguem uma distribuição normal vs $\mathrm{H}_{1}$ : os erros não seguem uma distribuição normal; (teste de Shapiro-Wilk); $\mathrm{H}_{0}$ : as variâncias dentro dos tratamentos são homogêneas vs $\mathrm{H}_{1}$ : as variâncias dentro dos tratamentos não são homogêneas (testes de Levene e de Bartlett).

Ainda com base na última coluna (Tabela 3), as taxas de decomposição celulolítica em todas as épocas foram consideradas baixas (abaixo de 50\%), exceto na $E_{4}(10 / 06 / 2012)$, que teve quase $50 \%$ do substrato degradado (algodão). Era de se esperar que uma atividade microbiana assim fosse justificada por um conjunto de chuvas corrido nesta época, o qual costuma quebrar o estado de dormência das populações microbianas pondo-as em atividade. Tal fenômeno, no entanto, não foi verificado, conforme pode ser observado na Figura 5, que mostra as chuvas ocorridas nesta época. Segundo Garcia et al. (1994), o baixo teor de matéria orgânica no solo é a principal causa da baixa atividade microbiana em solos de regiões semi-áridas. De fato, todas as áreas aqui estudadas apresentaram teores de M.O. baixos, ou seja, menores de $15 \mathrm{~g} \mathrm{dm}^{-3}$ (Tabela 2). Contudo, este proponente discorda veementemente deste ponto de vista, acreditando ser a disponibilidade hídrica o principal fator limitante à atividade microbiana do solo e o principal mecanismo desencadeador deste fenômeno em tais regiões. Segundo Alexander (1977), a umidade é o fator mais relevante sobre a atividade microbiana, regulando de várias maneiras os componentes do protoplasma, alterando as trocas gasosas e auxiliando no transporte e dissolução dos nutrientes do solo.

Com relação aos resultados de atividade microbiana, expressos em taxa de decomposição celulolítica, Luna et al. (2008), estudando duas áreas em diferentes idades de uso como pastagem nativa, no município de São João do Cariri, observaram valores mais elevados na área degradada (tratamento B) do que na área mais preservada (tratamento $A$ ), em quase todas as determinações por eles efetuadas, acreditando que, na área mais degradada a microbiota poderia estar investindo maior parte de sua energia em manutenção de sua biomassa do que em reprodução. Resultado similar 
foi aqui também observado, vito que a taxa de decomposição foi, na maioria das vezes, superior nos tratamentos com caprinos do que nas testemunhas, numa proporção de sete épocas de avaliação contra seis (Tabela 4).
Na Tabela 4 são apresentadas as análises estatísticas não-paramétricas e as comparações múltiplas das médias dos postos da decomposição de celulose em relação aos tratamentos.

Tabela 4. Análises estatísticas não-paramétricas (KRUSKAL-WALLIS, 1952) e comparações múltiplas das médias dos postos da decomposição de celulose em relação aos tratamentos em cada coleta nos anos 2012 e 2013.

\begin{tabular}{|c|c|c|c|c|c|c|c|}
\hline \multirow[t]{2}{*}{ Coleta } & \multirow[t]{2}{*}{ G.L. } & \multirow{2}{*}{$\begin{array}{c}\text { Valor h obtido } \\
\text { para a } \\
\text { estatística H } \\
\text { do teste de } \\
\text { Kruskal- } \\
\text { Wallis } \\
\text { H }\end{array}$} & \multirow{2}{*}{$\begin{array}{c}\text { Nível de } \\
\text { significância do } \\
\text { teste } \\
\operatorname{Pr}\left\{\chi^{2} \text { (G.L) } \geq h\right\}<p \\
\text { p-valor }\end{array}$} & \multicolumn{4}{|c|}{$\begin{array}{c}\text { Comparação dos valores médios } \\
\text { dos escores relativos aos } \\
\text { tratamentos }\end{array}$} \\
\hline & & & & $\mathbf{T}_{1}$ & $\mathbf{T}_{2}$ & $\mathbf{T}_{3}$ & $\mathbf{T}_{4}$ \\
\hline $\mathbf{E}_{\mathbf{1}}(27 / 01 / 12)$ & 2 & $11,305^{* *}$ & 0,0035 & $53,0 a$ & $33,4 b$ & $37,9 b$ & - \\
\hline $\mathbf{E}_{2}(12 / 03 / 12)$ & 2 & $6,834^{*}$ & 0,0328 & $52,7 a$ & $38,0 \mathrm{a}$ & $37,9 a$ & - \\
\hline $\mathbf{E}_{3}(26 / 04 / 12)$ & 2 & $14,160 * *$ & 0,0008 & $35,8 \mathrm{~b}$ & $42,8 \mathrm{ab}$ & $58,0 \mathrm{a}$ & - \\
\hline $\mathbf{E}_{4}(10 / 06 / 12)$ & 2 & $11,089 * *$ & 0,0039 & $54,9 a$ & $43,9 \mathrm{ab}$ & $33,2 b$ & - \\
\hline $\mathbf{E}_{\mathbf{5}}(25 / 07 / 12)$ & 2 & $30,265^{* *}$ & 0,0001 & $34,6 \mathrm{~b}$ & $36,0 \mathrm{~b}$ & $65,9 a$ & - \\
\hline $\mathbf{E}_{6}(08 / 09 / 12)$ & 2 & 4,620 & 0,0993 & $40,9 a$ & $40,7 a$ & $53,2 a$ & - \\
\hline $\mathbf{E}_{7}(23 / 10 / 12)$ & 2 & $10,675^{* *}$ & 0,0048 & $35,8 \mathrm{~b}$ & $35,0 \mathrm{~b}$ & $52,6 a$ & - \\
\hline $\mathbf{E}_{\mathbf{8}}(07 / 12 / 12)$ & 2 & $13,902^{* *}$ & 0,0010 & $38,2 b$ & $32,7 b$ & $55,0 \mathrm{a}$ & - \\
\hline $\mathbf{E}_{1}(21 / 01 / 13)$ & 3 & $21,991^{* *}$ & 0,0001 & $26,1 b$ & $33,1 b$ & $49,7 \mathrm{~b}$ & $60,8 \mathrm{a}$ \\
\hline $\mathbf{E}_{2}(09 / 03 / 13)$ & 3 & $19,459 * *$ & 0,0002 & $36,8 b$ & $44,3 \mathrm{~b}$ & $39,4 b$ & $64,5 a$ \\
\hline $\mathbf{E}_{3}(21 / 04 / 13)$ & 3 & $14,819 * *$ & 0,0020 & $70,5 a$ & $36,6 b$ & $48,5 b$ & $52,7 \mathrm{ab}$ \\
\hline $\mathbf{E}_{4}(03 / 06 / 13)$ & 3 & $14,477^{* *}$ & 0,0023 & $71,5 a$ & $43,9 b$ & $47,2 b$ & $46,9 \mathrm{~b}$ \\
\hline $\mathbf{E}_{\mathbf{5}}(20 / 07 / 13)$ & 3 & $41,820 * *$ & 0,0001 & $81,6 a$ & $69,6 a$ & $44,1 b$ & $32,6 b$ \\
\hline $\mathbf{E}_{6}(15 / 09 / 13)$ & 3 & $9,657^{* *}$ & 0,0217 & $47,8 \mathrm{~b}$ & $47,5 b$ & $67,8 \mathrm{a}$ & $62,7 \mathrm{ab}$ \\
\hline $\mathbf{E}_{7}(30 / 10 / 13)$ & 3 & $22,579 * *$ & 0,0001 & $75,4 a$ & $65,9 \mathrm{ab}$ & $54,3 \mathrm{bc}$ & $35,7 \mathrm{c}$ \\
\hline $\mathbf{E}_{\mathbf{8}}(14 / 12 / 13)$ & 3 & $26,116^{* *}$ & 0,0001 & $77,2 a$ & $63,7 b$ & $41,4 \mathrm{c}$ & $40,7 \mathrm{c}$ \\
\hline $\mathbf{E}_{\mathbf{9}}(27 / 01 / 14)$ & 3 & $18,120^{* *}$ & 0,0004 & $69,5 a$ & $59,0 a$ & $53,9 \mathrm{ab}$ & $34,1 \mathrm{~b}$ \\
\hline
\end{tabular}

$\mathbf{E}_{\mathbf{1}}, \mathbf{E}_{\mathbf{2}}, \mathbf{E}_{\mathbf{3}}, \ldots \mathbf{E}_{\mathbf{9}}$ - Épocas de coleta nos anos de 2012 e 2013. Obs.1: Escores médios seguidos das mesmas letras não diferem estatisticamente entre si, ao nível de 5\% de significância. Obs.2: Para os cálculos das diferenças mínimas significativas (d.m.s.) utilizadas para comparar os escores médios, levou-se em conta que os tratamentos não foram igualmente repetidos, as amostras são grandes e o nível de significância foi de 5\%, conforme Campos (1983, pg. 223-224).

Observou-se que em oito épocas de avaliação de $\mathrm{AD}\left(\mathrm{E}_{1}\right.$ e $\mathrm{E}_{4}$ de 2012 e $\mathrm{E}_{3}$, $E_{5}, E_{7}, E_{8}$ e $E_{9}$ de 2013), pelo menos um dos dois tratamentos com caprinos $\left(\mathrm{T}_{1}\right.$ oau $\mathrm{T}_{2}$ ) apresentou taxa de decomposição celulolítica maior do que em pelo menos uma das testemunhas $\mathrm{C}_{3}$ ou $\mathrm{T}_{4}$ ), diferindo estatisticamente ao nível de 5\% de significância, pelo teste não-paramétrico de Kruskal-Wallis.

Foi observado no primeiro ano de pesquisa (2012), que a atividade decompositora (AD) nos tratamento $\mathrm{T}_{1}$, $\mathrm{T}_{2}$ e $\mathrm{T}_{3}$, nos meses de março e setembro (épocas $E_{2}$ e $E_{6}$ ) não diferiram estatisticamente ao nível de $5 \%$ de 
significância. Foi observado também que estes meses estão entre aqueles que menos choveram no referido ano.

Nos meses de abril, junho, outubro e dezembro de 2012 (épocas $E_{3}$, $E_{5}, E_{7}$ e $E_{8}$ ) e nos meses de janeiro e março do ano seguinte (épocas $E_{1}$ e $E_{2}$ ) os valores dos escores médios da $\mathrm{AD}$ em pelo menos uma das testemunhas $\left(\mathrm{T}_{3}\right.$ ou $\mathrm{T}_{4}$ ) foram superiores aos valores dos tratamentos $\mathrm{T}_{1}$ e $\mathrm{T}_{2}$, diferindo estatisticamente ao nível de $5 \%$ de significância pelo teste não-paramétrico de Kruskal-Wallis. Nestes meses as precipitações foram muito baixas, sendo, respectivamente, $10,8,2,0,0,0,0$ e 2,6 $\mathrm{mm}$. Isto permite inferir que, quando os ecossistemas são menos perturbados, como as áreas III e IV (sem pastejo) a comunidade microbiana do solo torna-se mais resistente e, portanto, menos influenciada pela escassez hídrica, tendo maior capacidade de manterem sua atividade potencial, expressa em taxa de decomposição celulolítica, do que nos ecossistemas mais perturbados sob esta mesma condição, como nas áreas sob pastejo caprino (áreas I e II). É possível que esta superioridade na taxa de decomposição seja um reflexo da predominância em tais áreas de populações microbianas conhecidas como estrategistas " $\mathrm{k}$ ".

De acordo com a teoria de Andrews e Harris (1986), existem no universo da microbiota edáfica populações microbianas estrategista " $r$ " e " $k$ " que oscilam de acordo com as mudanças das condições ambientais. Os primeiros são chamados de oportunistas e fugitivos, reproduzem-se rapidamente, de forma exponencial e investem a maior parte de sua energia em reprodução quando as condições ambientais estão mais favoráveis, como a presença de chuvas, por exemplo; e desaparecem em condições adversas, como a estiagem. Apresentam, portanto, alta resiliência. Os estrategistas " $\mathrm{k}$ " reproduzem-se mais lentamente (de forma sigmoidal), são mais capazes de se manterem ativos em ambientes adversos, vivem em equilíbrio com o ambiente e investem a maior parte de sua energia em manutenção de sua biomassa, como em estruturas que lhe conferem maior capacidade adaptativa às condições do meio, por exemplo, e não em altas taxas reprodutivas. Apresentam, portanto, maior resistência frente às condições ambientais de estresse ou distúrbio, como as condições de estresse hídrico registradas nas épocas acima mencionadas.

\section{Biomassa microbiana, respiração basal, $\mathrm{qCO}_{2}$ e $\mathrm{C}_{\text {mic }}$ : $\mathrm{C}_{\text {org }}$ \\ Os resultados das análises} estatísticas para os parâmetros $\mathrm{BM}, \mathrm{AR}$, $\mathrm{qCO}_{2}$ e $\mathrm{C}_{\text {mic }}$ : $\mathrm{C}_{\text {org }}$ encontram-se na Tabela 5, para os dados do experimento com uma testemunha (dados de 2012) e na Tabela 5, para o experimento com duas testemunhas (dados de 2013). Observese que, para as variáveis transformadas dos dois experimentos, Tabelas 5 e 6, os coeficientes de variação foram todos abaixo de $20 \%$, isto é, se situaram entre 4,2 e 17,3 para o experimento com uma testemunha $\left(\mathrm{T}_{3}\right)$ e entre 7,5 e 15,8 para o experimento com duas testemunhas $\left(\mathrm{T}_{3}\right.$ e $\mathrm{T}_{4}$ ). Simultaneamente, constatou-se a normalidade dos dados transformados pelo teste de Shapiro-Wilk (1965), pois, os níveis descritivos ( $\mathrm{p}$-valor) foram todos maiores que 0,05 , levando a concluir que as hipóteses de normalidade das variáveis transformadas não foram rejeitadas ao nível de $5 \%$ de significância. 
Tabela 5. Resultados do coeficiente de variação, da estatística W de Shapiro-Wilk e do nível descritivo do teste ( $p$-valor), associados às variáveis originais e transformadas para o experimento com uma testemunha (2012).

\begin{tabular}{lcccc}
\hline \multirow{2}{*}{ Variáveis } & \multirow{2}{*}{ C.V.(\%) } & \multicolumn{2}{c}{ Teste de Shapiro-Wilk } \\
\cline { 4 - 5 } Originais & $\mathbf{B M}$ & 45,8 & $\mathrm{~W}$ & P-Valor \\
& $\mathbf{R B}$ & 19,6 & 0,9023 & 0,0241 \\
& $\mathbf{q C O}_{\mathbf{2}}$ & 56,2 & 0,9538 & 0,3274 \\
& $\mathbf{C}_{\text {mic: }}$ org & 112,3 & 0,9400 & 0,1627 \\
\cline { 2 - 5 } Transformadas & $\mathbf{B M}$ & 8,4 & 0,8685 & 0,0049 \\
& $\mathbf{R B}$ & 4,2 & 0,9405 & 0,1670 \\
& $\mathbf{q C O}$ & 6,7 & 0,9716 & 0,7062 \\
& $\mathbf{C}_{\text {mic }}$ : $\mathbf{C}_{\text {org }}$ & 17,3 & 0,9679 & 0,6151 \\
& & & 0,9537 & 0,3247 \\
\hline
\end{tabular}

Tabela 6. Resultados do coeficiente de variação, da estatística W de Shapiro-Wilk e do nível descritivo do teste ( $\mathrm{p}$-valor), associados às variáveis originais e transformadas para o experimento com duas testemunhas (2013).

\begin{tabular}{lcccc}
\hline \multirow{2}{*}{ Variáveis } & \multirow{2}{*}{ C.V.(\%) } & \multicolumn{2}{c}{ Teste de Shapiro-Wilk } \\
\cline { 4 - 5 } Originais & BM & 28,2 & W & P-Valor \\
& $\mathbf{R B}$ & 34,1 & 0,9787 & 0,7011 \\
& $\mathbf{q C O} \mathbf{C O}_{2}$ & 117,7 & 0,9221 & $\mathbf{0 , 0 1 4 6}$ \\
& $\mathbf{C}_{\text {mic }} \mathbf{C}_{\text {org }}$ & 40,4 & 0,7969 & $<\mathbf{0 , 0 0 0 1}$ \\
\multirow{4}{*}{ Transformadas } & $\mathbf{B M}$ & 9,4 & 0,9481 & 0,0912 \\
& $\mathbf{R B}$ & 7,5 & 0,9766 & 0,6305 \\
& $\mathbf{q C O}$ & 15,8 & 0,9449 & 0,0724 \\
& $\mathbf{C}_{\text {mic }} \mathbf{C}_{\text {org }}$ & 10,4 & 0,9497 & 0,1024 \\
& & & 0,9776 & 0,6649 \\
\hline
\end{tabular}

Atendidas às suposições de estabilidade da variância e de normalidade dos erros, procedeu-se à análise de variância com o objetivo de testar as seguintes hipótese:

$\mathrm{H}_{0}(\tau)$ Os tratamentos não têm efeitos sobre a variável resposta.

$\mathrm{H}_{0}(\beta)$ : As épocas de avaliação não têm efeitos sobre a variável resposta.

$\mathrm{H}_{0}(1)$ : A média da variável resposta relativa aos tratamentos $\mathrm{T}_{1}$ e $\mathrm{T}_{2}$ combinados é igual à média da testemunha. [Contraste: $\left(\mathrm{T}_{1}+\mathrm{T}_{2}\right)$ vs $\mathrm{T}_{3}$, para o Experimento 1].

$\mathrm{H}_{0}(2)$ A média da variável resposta no tratamento 1 é igual à média da variável resposta no tratamento 2 . (Contraste: $\mathrm{T}_{1}$ vs $\mathrm{T}_{2}$, para os Experimentos 1 e 2).
$\mathrm{H}_{0}(3): \quad$ A média da variável resposta relativa aos tratamentos $\mathrm{T}_{1}$ e $\mathrm{T}_{2}$ combinados é igual à média das testemunhas combinadas [Contraste: $\left(\mathrm{T}_{1}+\mathrm{T}_{2}\right)$ vs $\left(\mathrm{T}_{3}+\mathrm{T}_{4}\right)$ no Experimento 2].

$\mathrm{H}_{0}(4)$ : As médias da variável resposta relativa às testemunhas são iguais. (Contraste: $\mathrm{T}_{3}$ vs $\mathrm{T}_{4}$, para $\mathrm{o}$ Experimento 2).

Os resultados das análises de variância que objetivaram testar as hipóteses anteriormente mencionadas encontram-se nas Tabelas 7 e 8.

Ao contrastarem-se os valores de $\mathrm{BM}, \mathrm{RB}$ e $\mathrm{qCO}_{2}$ dos tratamentos $\left(\mathrm{T}_{1}+\mathrm{T}_{2}\right)$ com a testemunha $\left(\mathrm{T}_{3}\right)$, verificou-se que houve diferenças significativas ao nível de $1 \%$. De forma semelhante, ao realizarse o contraste entre os tratamentos $\left(\mathrm{T}_{1}\right.$ vs 
$\mathrm{T}_{2}$ ), observou-se que os valores de $\mathrm{BM}$, $\mathrm{qCO}_{2}$ e a relação $\mathrm{C}_{\text {mic: }}$ : $\mathrm{C}_{\text {org }}$ também diferiram ao mesmo nível de significância (1\%). A BM e a relação $C_{\text {mic: }}$ : $\mathrm{C}_{\text {org }}$ praticamente não variaram entre as épocas de avaliação, durante o primeiro ano de experimento, conforme podem ser observadas na Tabela 7.

Com relação às médias de $\mathrm{BM}, \mathrm{RB}$, $\mathrm{qCO}_{2}$ e $\mathrm{C}_{\text {mic }}: \mathrm{C}_{\text {org }}$ entre os tratamentos, verificaou-se que a $B M$ e a relação $C_{\text {mic }}$ : $\mathrm{C}_{\text {org }}$ em $\mathrm{T}_{1}$ foi igual a $\mathrm{T} 3$, sendo ambas superiores a $\mathrm{T}_{2}$. Com relação à $\mathrm{RB}$ e ao $\mathrm{qCO}_{2}$, observou-se que o primeiro parâmetro foi em $T_{1}$ igual a $T_{2}$, sendo ambos superiores a $\mathrm{T}_{3}$, Já o segundo parâmetro, foi maior em $\mathrm{T}_{2}>\mathrm{T}_{1}>\mathrm{T}_{3}$ (Tabela 7).

Tabela 7. Resultados da análise e variância para testar os efeitos dos contrastes de interesse, dos tratamentos e das épocas de avaliação; do teste de Tukey para comparação das médias duas a duas com respectivas D.M.S., obtidos a partir dos dados do experimento 1 (2012).

\begin{tabular}{|c|c|c|c|c|c|}
\hline \multirow{2}{*}{ F. Variação } & \multirow{2}{*}{ G.L. } & \multicolumn{4}{|c|}{ Quadrados médios/Médias por variável transformada } \\
\hline & & BM & RB & $\mathrm{qCO}_{2}$ & $\mathrm{C}_{\text {mic }}: \mathrm{C}_{\text {org }}$ \\
\hline \multirow{2}{*}{$\begin{array}{l}\left(T_{1}+T_{2}\right) \text { vs } T_{3} \\
T_{1} \text { vs } T_{2}\end{array}$} & 1 & $0,2168 * *$ & $0,0274 * *$ & $0,2388 * *$ & 0,0068 \\
\hline & 1 & $0,1736 * *$ & 0,0008 & $0,1732^{* *}$ & $0,1036^{* *}$ \\
\hline \multirow{3}{*}{$\begin{array}{l}\text { Tratamento } \\
\text { Época } \\
\text { Resíduo }\end{array}$} & (2) & $0,4679 * *$ & $0,0333^{* *}$ & $0,5506^{* *}$ & $0,0552 * *$ \\
\hline & 7 & $0,0496^{*}$ & $0,0874^{* *}$ & $0,1976^{* *}$ & 0,0057 \\
\hline & 14 & 0,0173 & 0,0045 & 0,0102 & 0,0032 \\
\hline \multirow{3}{*}{ Médias (Trat.) } & $\mathbf{T}_{1}$ & $1,129 \mathrm{a}$ & $1,144 \mathrm{a}$ & $1,000 \mathrm{~b}$ & $0,395 \mathrm{a}$ \\
\hline & $\mathbf{T}_{2}$ & $0,920 \mathrm{~b}$ & $1,130 \mathrm{a}$ & $1,208 \mathrm{a}$ & $0,234 \quad b$ \\
\hline & $\mathbf{T}_{3}$ & $1,226 \mathrm{a}$ & $1,065 \mathrm{~b}$ & $0,893 \quad \mathrm{c}$ & $0,350 \mathrm{a}$ \\
\hline \multirow[t]{4}{*}{ D.M.S (5\%) (Trat.) } & - & 0,120 & 0,062 & 0,091 & 0,074 \\
\hline & $\mathbf{E}_{1}$ & $1,071 \mathrm{ab}$ & 1,058 bc & 0,973 bc & $0,307 \mathrm{a}$ \\
\hline & $\mathbf{E}_{2}$ & $1,158 \mathrm{ab}$ & $1,037 \mathrm{bc}$ & $0,931 \quad c$ & $0,328 \mathrm{a}$ \\
\hline & $\mathbf{E}_{3}$ & $1,108 \mathrm{ab}$ & $1,005 \mathrm{c}$ & $0,913 \mathrm{c}$ & $0,406 \mathrm{a}$ \\
\hline \multirow[t]{5}{*}{ Médias (Época) } & $\mathbf{E}_{4}$ & $1,229 \mathrm{a}$ & $1,080 \mathrm{bc}$ & $0,963 \mathrm{bc}$ & $0,369 \mathrm{a}$ \\
\hline & $\mathbf{E}_{5}$ & $1,097 \mathrm{ab}$ & $0,995 \mathrm{c}$ & $0,894 \quad c$ & $0,321 \mathrm{a}$ \\
\hline & $\mathbf{E}_{6}$ & $1,073 \mathrm{ab}$ & $1,142 \mathrm{~b}$ & 1,034 bc & $0,299 \mathrm{a}$ \\
\hline & $\mathbf{E}_{7}$ & $0,915 \mathrm{~b}$ & $1,287 \mathrm{a}$ & $1,401 \mathrm{a}$ & $0,263 \mathrm{a}$ \\
\hline & $\mathbf{E}_{8}$ & $1,084 \mathrm{ab}$ & $1,301 \mathrm{a}$ & $1,161 \mathrm{~b}$ & $0,321 \mathrm{a}$ \\
\hline D.M.S(5\%)(Época) & & 0,265 & 0,135 & 0,201 & 0,163 \\
\hline
\end{tabular}

$\mathbf{E}_{1}, \mathbf{E}_{2}, \mathbf{E}_{3}, \ldots \mathbf{E}_{8}$ - Épocas de coleta no ano de 2012. “*” e “**” efeito estatisticamente significativo ao nível de 5\% e 1\%, respectivamente. D.M.S. (5\%) diferença mínima significativa calculada pelo método de Tukey a 5\% de significância. Obs.: Médias seguidas das mesmas letras não diferem estatisticamente entre si, pelo teste de Tukey, ao nível de 5\% de significância.

Na Tabela 7, evidenciou-se que os tratamentos tiveram efeitos estatisticamente significativos, ao nível de $1 \%$, sobre todas as variáveis estudadas (BM, RB, $\mathrm{qCO}_{2}$ e $\mathrm{C}_{\text {mic }}: \mathrm{C}_{\text {org }}$ ). Por outro lado, os efeitos das épocas de avaliação sobre as variáveis estudadas só não foram estatisticamente significativos para a variável $\mathrm{C}_{\text {mic }}$ : $\mathrm{C}_{\text {org }}$ do Experimento 1 (2012). 
Tabela 8. Resultados da análise de variância para testar os efeitos dos contrastes de interesse, dos tratamentos e das épocas de avaliação; do teste de Tukey para comparação das médias duas a duas com respectivas D.M.S, obtidos a partir dos dados do experimento 2 (2013).

\begin{tabular}{|c|c|c|c|c|c|}
\hline \multirow{2}{*}{ F. Variação } & \multirow{2}{*}{ G.L. } & \multicolumn{4}{|c|}{ Quadrados médios/Médias por variável transformada } \\
\hline & & BM & RB & $\mathrm{qCO}_{2}$ & $C_{\text {mic }}: C_{\text {org }}$ \\
\hline$\left(T_{1}+T_{2}\right) v s\left(T_{3}+T_{4}\right)$ & 1 & 0,0408 & 0,00737 & 0,0319 & 0,0025 \\
\hline $\mathbf{T}_{1}$ Vs $\mathbf{T}_{2}$ & 1 & 0,0538 & 0,00381 & 0,0180 & $0,0603^{* *}$ \\
\hline $\mathbf{T}_{3}$ Vs $\mathbf{T}_{4}$ & 1 & $0,0918^{*}$ & 0,00001 & 0,0113 & $0,0075^{*}$ \\
\hline Tratamento & (3) & $0,0621^{*}$ & 0,0037 & 0,0204 & $0,0234^{* *}$ \\
\hline Época & 8 & $0,3463^{* *}$ & $0,0912^{* *}$ & $0,1693^{* *}$ & $0,0401^{* *}$ \\
\hline Resíduo & 24 & 0,0147 & 0,0066 & 0,0214 & 0,0016 \\
\hline \multirow{4}{*}{ Médias (Trat.) } & $\mathbf{T}_{1}$ & $1,304 \mathrm{ab}$ & $1,105 \mathrm{a}$ & $0,923 \mathrm{a}$ & $0,434 \mathrm{a}$ \\
\hline & $\mathbf{T}_{2}$ & $1,194 \mathrm{~b}$ & $1,076 \mathrm{a}$ & $0,986 \mathrm{a}$ & $0,319 \quad c$ \\
\hline & $\mathbf{T}_{3}$ & $1,300 \mathrm{a}$ & $1,061 \mathrm{a}$ & $0,870 \mathrm{a}$ & $0,414 \mathrm{ab}$ \\
\hline & $\mathbf{T}_{4}$ & $1,245 \mathrm{ab}$ & $1,062 \mathrm{a}$ & $0,920 \mathrm{a}$ & $0,373 \mathrm{~b}$ \\
\hline DMS.(5\%) (Trat.) & - & 0,158 & 0,106 & 0,190 & 0,052 \\
\hline \multirow{9}{*}{ Médias (Época) } & $\mathbf{E}_{1}$ & $1,191 \mathrm{~b}$ & $1,050 \mathrm{~b}$ & $0,917 \mathrm{~b}$ & $0,348 \mathrm{a}$ \\
\hline & $\mathbf{E}_{2}$ & $1,140 \mathrm{~b}$ & $1,018 \mathrm{~b}$ & $0,915 \mathrm{~b}$ & $0,348 \mathrm{ab}$ \\
\hline & $\mathbf{E}_{3}$ & $1,155 \mathrm{~b}$ & $1,031 \mathrm{~b}$ & $0,910 \mathrm{~b}$ & $0,332 \quad c$ \\
\hline & $\mathbf{E}_{4}$ & $1,155 \mathrm{~b}$ & $0,981 \mathrm{~b}$ & $0,857 \mathrm{~b}$ & $0,352 \quad c$ \\
\hline & $\mathbf{E}_{5}$ & $1,522 \mathrm{a}$ & $0,963 \mathrm{~b}$ & $0,751 \mathrm{~b}$ & $0,459 \mathrm{ab}$ \\
\hline & $\mathbf{E}_{6}$ & $1,061 \mathrm{ab}$ & $0,922 \mathrm{~b}$ & $0,980 \mathrm{~b}$ & $0,302 \quad c$ \\
\hline & $\mathbf{E}_{7}$ & $0,902 \mathrm{~b}$ & $1,286 \mathrm{a}$ & $1,433 \mathrm{a}$ & $0,259 \quad \mathrm{c}$ \\
\hline & $\mathbf{E}_{8}$ & $1,626 \mathrm{a}$ & $1,061 \mathrm{~b}$ & $0,758 \mathrm{~b}$ & $0,499 a$ \\
\hline & $\mathbf{E}_{9}$ & $1,794 \mathrm{a}$ & $1,370 \mathrm{a}$ & $0,805 \mathrm{~b}$ & $0,565 \mathrm{a}$ \\
\hline D.M.S.(5\%) (Época) & - & 0,291 & 0,195 & 0,351 & 0,096 \\
\hline
\end{tabular}

$\mathbf{E}_{1}, \mathbf{E}_{2}, \mathbf{E}_{3}, \ldots \mathbf{E}_{9}$ - Épocas de coleta no ano de 2013. “*” e "**" efeito estatisticamente significativo ao nível de 5\% e 1\%, respectivamente. D.M.S. (5\%) diferença mínima significativa calculada pelo método de Tukey a 5\% de significância. Obs.: Médias seguidas das mesmas letras não diferem estatisticamente entre si, pelo teste de Tukey, ao nível de 5\% de significância.

Também, nas Tabelas 7 e 8 , o contraste testemunhas versus tratamentos foi estatisticamente significativo ao nível de $1 \%$ de significância para as variáveis transformadas $\mathrm{BM}, \mathrm{RB}$ e $\mathrm{qCO}_{2}$ no Experimento 1 (2012), sendo que o mesmo não foi verificado para estas mesmas variáveis no Experimento 2 (2013) e para a variável $C_{\text {mic }}$ : $C_{\text {org }}$ nos dois experimentos. $O$ contraste $\mathrm{T}_{1} v s \mathrm{~T}_{2}$ foi estatisticamente significativo para as variáveis transformadas $\mathrm{BM}$ e $\mathrm{qCO}_{2}$ no Experimento 1 e para $\mathrm{C}_{\text {mic }}$ : $\mathrm{C}_{\text {org }}$ nos dois experimentos, sendo observados maiores valores médios para o tratamento $T_{1}$ nas variáveis $\mathrm{BM}, \mathrm{C}_{\text {mic }}$ : $\mathrm{C}_{\text {org }}$ e menor valor para a variável $\mathrm{qCO}_{2}$ do Experimento 1 . Este contraste não foi estatisticamente significativo para as variáveis RB nos dois experimentos, $\mathrm{BM}$ e $\mathrm{qCO}_{2}$ no experimento 2. Neste mesmo experimento, o contraste entre as médias das testemunhas $\mathrm{T}_{3}$ vs $\mathrm{T}_{4}$ não apresentou significância estatística, ao nível de 5\% pelo teste $\mathrm{F}$, para as variáveis $\mathrm{RB}$ e $\mathrm{qCO}_{2}$. Porém, para as variáveis $\mathrm{BM}$ e $\mathrm{C}_{\text {mic }}$ : $\mathrm{C}_{\text {org }}$ este contraste foi estatisticamente significativo, ao nível de $5 \%$ de significância, constatando-se maiores médias para a testemunha $\mathrm{T}_{3}$. Ainda nas Tabelas 7 e 8, estão apresentadas as estimativas das médias das variáveis transformadas relativas aos tratamentos e épocas de avaliação, bem como suas respectivas diferenças mínimas significativas calculadas pelo método de Tukey ao nível de 5\% de significância. A comprovação das diferenças estatisticamente significativas entre as 
médias são identificadas pelo acompanhamento das letras diferentes.

Observando-se a Tabela 7 (dados de 2012), os resultados mostraram que o solo de $\mathrm{T}_{3}$ tem maior $\mathrm{BM}$ do que os solos de $\mathrm{T}_{2}$ e que, os solos de $\mathrm{T}_{1}$ e $\mathrm{T}_{2}$ apresentaram valores mais elevados de respiração basal (RB) e de $\mathrm{qCO}_{2}$ do que o solo de $T_{3}$, evidenciando que suas populações microbianas investem a maior parte de sua energia para sua manutenção. Condição esta que reflete maior estresse da microbiota edáfica dos referidos solos. Considera-se ainda o fato de que neste ano houve um maior, mas não comprovado estatisticamente, aporte de serapilheira $\left(23,30\right.$ e 11,10 g.m ${ }^{-2}$, que correspondeu a 2.795,72 e 1.331,56 kg.ha'.ano ${ }^{-1}$, nos tratamentos $\mathrm{T}_{1}$ e $\mathrm{T}_{2}$, respectivamente. Vide Tabela 1 do capítulo 2), tendo as taxas de decomposição celulolítica, por isso, apresentado valores mais elevados dentre os três tratamentos $(0,172$ g.45 dias $^{-1}$ e 0,116 g.45 dias $^{-1}$, que corresponde a 1,39 g. ano-1 e 0,94 g. ano ${ }^{1}$, repctivamente em $\mathrm{T}_{1}$ e $\mathrm{T}_{2}$ ) para o ano de 2012 (Tabela 3). Estes resultados mostram que a microbiota do solo de $\mathrm{T}_{1}$ e $\mathrm{T}_{2}$ parece estar em condições menos favoráveis de manutenção do que a microbiota do solo de $\mathrm{T}_{3}(0,109$ g. 45 dias $^{-1}=0,884$ g. ano-1). Tal dedução é fortalecida pelos maiores valores de $\mathrm{qCO}_{2}$ em $\mathrm{T}_{1}$ e $\mathrm{T}_{2}$, que refletem maior gasto de energia, comparativamente ao solo de $\mathrm{T}_{3}$, que obteve menor valor de $\mathrm{qCO}_{2}$.

Em suma, o quociente respiratório $\left(\mathrm{qCO}_{2}\right)$ de um solo, que traduz o gasto de energia da microbiota, indica que, à medida que a biomassa microbiana se torna mais eficiente, menor será a quantidade de $\mathrm{C}$ perdida na forma de $\mathrm{CO}_{2}$ pela respiração, em detrimento de uma fração significativa de $\mathrm{C}$ ser incorporada à biomassa microbiana. Assim, uma biomassa microbiana "eficiente" tem menor taxa de respiração $\left(\mathrm{T}_{3}\right)$ em relação a uma biomassa "ineficiente" ( $\mathrm{T}_{1}$ e $\left.\mathrm{T}_{2}\right)$.
Segundo Martins et al. (2010), ao estudarem atributos de solos e sua relação com o processo de desertificação no Semiárido de Pernambuco, concluíram que, tanto o $\mathrm{qCO}_{2}$ quanto a biomassa microbiana, mostraram-se mais sensíveis à degradação ambiental e sugeriram que tais atributos poderiam ser usados como indicadores de qualidade do solo.

Ainda na Tabela 7, existe maior quantidade de carbono microbiano como parte do carbono orgânico total do solo ( $\mathrm{C}_{\text {mic }}: \mathrm{C}_{\text {org }}$ ) em $\mathrm{T}_{1}$ e $\mathrm{T}_{3}$ do que em $\mathrm{T}_{2}$, mostrando que os micro-organismos destes solos estão armazenando mais carbono em sua BM e, consequentemente, contribuindo menos para o aquecimento global (efeito estufa).

Geralmente, a relação $\mathrm{C}_{\text {mic }}$ : $\mathrm{C}_{\text {org }}$ têm alta relação com a BM em condições de campo, ou seja, onde a BM é mais robusta, a relação $\mathrm{C}_{\text {mic }}$ : $\mathrm{C}_{\text {org }}$ tende a ser também (vide os dados de $\mathrm{BM}$ e de $\mathrm{C}_{\text {mic: }}$ : $\mathrm{C}_{\text {org }}$ nos tratamento $\mathrm{T}_{1}, \mathrm{~T}_{2}$ e $\mathrm{T}_{3}$, na Tabela 6). Contrariamente, onde a $\mathrm{BM}$ é mais robusta, o $\mathrm{qCO}_{2}$ geralmente tende a ser mais baixo, principalmente em ambientes equilibrados. Ainda com base na referida tabela a relação $\mathrm{C}_{\text {mic }}$ : $\mathrm{C}_{\text {org }}$ não diferiu estatisticamente ao longo das épocas de coletas $\left(E_{1}, E_{2}, E_{3}, \ldots E_{8}\right)$.

Martins et al., (2010), ao estudarem áreas em processo de desertificação no Estado de Pernambuco, destacaram a BM como um dos atributos mais sensíveis ao avanço da degradação, podendo, segundo eles, ser utilizada como indicador do nível de degradação do solo. Tal atributo foi aqui utilizado com este propósito, juntamente com outros parâmetros que, a partir dele foram determinados $\left(\mathrm{RB}, \mathrm{o} \mathrm{qCO}_{2}\right.$ e a relação $\mathrm{C}_{\text {mic }}$ : $\mathrm{C}_{\text {org }}$ ).

Loureiro (2012) observou que as áreas com baixos níveis de antropização apresentaram menor perda relativa de carbono pela respiração microbiana e repercutiu no baixo índice de quociente metabólico $\left(\mathrm{qCO}_{2}\right)$, ilustrando o seu papel na dinâmica de carbono nos 
ecossistemas terrestres. Wardle e Ghani (1995) observaram que o aumento do $\mathrm{qCO}_{2}$ em solos de ecossistemas perturbados indica uma resposta da microbiota do solo às condições adversas, sugerindo ineficiência da biomssa microbiana no uso do carbono do solo.

Estas observações estão de acordo com os resultados aqui obtidos, uma vez que o solo de $\mathrm{T}_{1}$, com maior densidade de caprinos é, por isso, mais antropizado do que o solo de $\mathrm{T}_{3}$ (sem caprinos). De forma mais generalizada, solos com baixo $\mathrm{qCO}_{2}$ refletem economia de energia e eficiência em sua utilização e, supostamente, indica estabilidade e equilíbrio destes. Contrariamente, valores elevados são indicativos de ecossistemas submetidos a alguma condição de estresse ou de distúrbio (Anderson e Domsch, 1985), como as condições aqui encontradas de adensamento de caprinos $\left(\mathrm{T}_{1} \mathrm{e} \mathrm{T}_{2}\right)$.

Anderson e Domsch (1990;1993) observaram que $\mathrm{o} \quad \mathrm{qCO}_{2}$ também mostrou-se útil na indicação de condições adversas, como a acidez no solo (maior $\mathrm{qCO}_{2}$ ), quando comparadas às condições de neutralidade (menor $\mathrm{qCO}_{2}$ ). Estas observações estão de acordo com os resultados aqui obtidos, uma vez que os solos de $\mathrm{T}_{1}$ e $\mathrm{T}_{2}$, por apresentarem maior acidez $(\mathrm{pH}=\mathrm{a} \quad 6,03$ e 5,88, respectivamente) do que o solo de $\mathrm{T}_{3}$ $(\mathrm{pH}=6,43)$, apresentaram valores de $\mathrm{qCO}_{2}$ mais elevados $(1,000$ e $1,208 \mathrm{mg} \mathrm{C}$ $\mathrm{CO}_{2}$. 100 g-1 de solo seco S.E., respectivamente), indicando biomassa microbiana estressada.

No primeiro ano de experimento (2012), o solo de $T_{2}$, que teve o menor valor de $\mathrm{BM}\left(0,920 \mathrm{mg}\right.$ de $\mathrm{C}-\mathrm{CO}_{2} \cdot 100 \mathrm{~g}^{-1}$ de solo S.E.) e maior valor RB $(1,130 \mathrm{mg}$ de C- $\mathrm{CO}_{2} .100 \mathrm{~g}^{-1}$ de solo S.E.) igual ao do solo de $\mathrm{T}_{1}\left(1,144 \mathrm{mg}\right.$ de C- $\mathrm{CO}_{2} \cdot 100 \mathrm{~g}^{-1}$ de solo S.E.), apresentou o maior valor de $\mathrm{qCO}_{2}\left(1,208 \mathrm{mg}\right.$ de C- $\mathrm{CO}_{2} \cdot \mathrm{g}^{-1}$ de BM. $\left.\mathrm{h}^{-1}\right)$, que indica estar sua microbiota investindo a maior parte de sua energia (armazenada sob forma de carbono) em sua manutenção. Estes são indicadores de que a microbiota do solo de $\mathrm{T}_{2}$ também está em condições menos favoráveis do que a microbiota de $\mathrm{T}_{3}$ (Tabela 6).

Existe um percentual de carbono microbiano como parte do carbono orgânico total do solo $\left(\mathrm{C}_{\text {mic: }}\right.$ : $\left.\mathrm{C}_{\text {org }}\right)$ maior em $\mathrm{T}_{3}$ e $\mathrm{T}_{1}(0,395$ e 0,350$)$ do que em $\mathrm{T}_{2}$ $(0,234)$, sendo os resultados de $\mathrm{BM}$ (maior dos três), $\mathrm{RB}$ e $\mathrm{qCO}_{2}$ (menores dos três) indicativos de que a microbiota do solo de $\mathrm{T}_{3}$ apresentou maior eficiência no armazenamento e utilização do carbono para sua manutenção, enquanto a microbiota do solo de $\mathrm{T}_{2}$ apresenta resultados opostos (Tabela 6)

Resultados similares foram obtidos por Luna et al. (2008), em estudo sobre microbiota de solos do Cariri da Paraíba, em que no solo considerado mais produtivo e menos degradado (à semelhança do solo da caatinga testemunha do presente trabalho, ou seja, o tratamento $\mathrm{T}_{3}$, sem caprinos), a biomassa apresentou-se mais elevada; e o solo menos produtivo e mais degradado (à semelhança do solo da caatinga deste presente trabalho, ou seja, os tratamentos $\mathrm{T}_{1} \mathrm{e} \mathrm{T}_{2}$, com caprinos) apresentou valores mais elevados de respiração basal e de $\mathrm{qCO}_{2}$, indicando maior gasto de energia para manutenção de suas populações microbianas. No mesmo estudo realizado pelos autores acima, a taxa de decomposição celulolítica (AD) foi mais elevada no solo da área mais impactada pelo pastejo caprino (área sob esta condição há mais de 40 anos) do que na área menos impactada (pastejo há 20 anos), à semelhança do solo de $\mathrm{T}_{1}$ e $\mathrm{T}_{2}$, do presente estudo, indicando maior gasto de energia.

Observando a Tabela 8, não foram encontradas evidências estatisticamente significativas, ao nível de $1 \%$, do efeito dos tratamentos sobre as variáveis $\mathrm{RB}$ e $\mathrm{qCO}_{2}$, no Experimento 2 (2013). Neste ano, o solo de $\mathrm{T}_{3}$ também apresentou maior $\operatorname{BM}(1,30)$ do que o solo de $\mathrm{T}_{2}(1,194)$ e valor mais baixo de $C_{\text {mic }}: C_{\text {org, }}(0,319)$, evidenciando que suas 
populações microbianas investem a maior parte de sua energia para sua manutenção. Esta condição indica maior estresse da microbiota edáfica do referido solo.

Estes resultados mostram que a microbiota do solo de $\mathrm{T}_{2}$ parece estar em condições menos favoráveis de manutenção do que a microbiota do solo de $\mathrm{T}_{3}$
Nas Tabelas 9 e 10, estão apresentadas as estimativas das médias das variáveis originais relativas aos tratamentos e épocas de avaliação. Estas estimativas não foram consideradas nas análises estatísticas realizadas. Elas serviram apenas como referência comparativa visual entre as médias das variáveis transformadas e originais.

Tabela 9. Estimativas das médias dos valores observados das variáveis originais relativas aos tratamentos e época de avaliação para o experimento 1 (2012).

\begin{tabular}{crrrc}
\hline \multirow{2}{*}{ Trat./Época } & \multicolumn{4}{c}{ Médias das variáveis originais } \\
\cline { 2 - 5 } & \multicolumn{1}{c}{$\mathbf{B M}$} & $\mathbf{R B}$ & $\mathbf{q} \mathbf{C O}_{\mathbf{2}}$ & $\mathbf{C}_{\mathbf{m i c}}: \mathbf{C}_{\text {org }}$ \\
\hline $\mathbf{T}_{\mathbf{1}}$ & 8,874 & 9,194 & 5,923 & 0,028 \\
$\mathbf{T}_{\mathbf{2}}$ & 3,389 & 9,288 & 13,224 & 0,003 \\
$\mathbf{T}_{\mathbf{3}}$ & 12,865 & 7,120 & 3,218 & 0,016 \\
\hline $\mathbf{E}_{\mathbf{1}}(27 / 01 / 12)$ & 7,110 & 6,487 & 4,623 & 0,010 \\
$\mathbf{E}_{\mathbf{2}}(12 / 03 / 12)$ & 10,637 & 5,960 & 4,043 & 0,014 \\
$\mathbf{E}_{\mathbf{3}}(26 / 04 / 12)$ & 8,363 & 5,173 & 3,357 & 0,041 \\
$\mathbf{E}_{\mathbf{4}}(10 / 06 / 12)$ & 15,420 & 7,977 & 5,357 & 0,024 \\
$\mathbf{E}_{\mathbf{5}}(25 / 07 / 12)$ & 7,703 & 4,960 & 2,903 & 0,011 \\
$\mathbf{E}_{\mathbf{6}}(08 / 09 / 12)$ & 6,990 & 9,013 & 6,233 & 0,008 \\
$\mathbf{E}_{\mathbf{7}}(23 / 10 / 12)$ & 3,317 & 14,453 & 22,477 & 0,005 \\
$\mathbf{E}_{\mathbf{8}}(07 / 12 / 12)$ & 7,467 & 15,147 & 10,643 & 0,011 \\
\hline
\end{tabular}

$\mathbf{E}_{1}, \mathbf{E}_{2}, \mathbf{E}_{3}, \ldots \mathbf{E}_{8}$ - Épocas de coleta no ano de 2012.

Tabela 10. Estimativas das médias dos valores observados das variáveis originais relativas aos tratamentos e época de avaliação para o experimento 2 (2013).

\begin{tabular}{crrrc}
\hline \multirow{2}{*}{ Trat./Época } & \multicolumn{4}{c}{ Médias das variáveis originais } \\
\cline { 2 - 5 } & $\mathbf{B M}$ & $\mathbf{R B}$ & $\mathbf{q} \mathbf{C O}_{\mathbf{2}}$ & $\mathbf{C}_{\mathbf{m i c}} \mathbf{\mathbf { C } _ { \text { org } }}$ \\
\hline $\mathbf{T}_{\mathbf{1}}$ & 19,878 & 8,071 & 4,802 & 0,042 \\
$\mathbf{T}_{\mathbf{2}}$ & 17,652 & 8,247 & 8,631 & 0,017 \\
$\mathbf{T}_{\mathbf{3}}$ & 24,159 & 7,653 & 2,999 & 0,032 \\
$\mathbf{T}_{\mathbf{4}}$ & 16,542 & 7,232 & 4,382 & 0,023 \\
\hline $\mathbf{E}_{\mathbf{1}}(21 / 01 / 13)$ & 11,733 & 6,240 & 3,778 & 0,016 \\
$\mathbf{E}_{\mathbf{2}}(09 / 03 / 13)$ & 9,580 & 5,478 & 3,592 & 0,016 \\
$\mathbf{E}_{\mathbf{3}}(21 / 04 / 13)$ & 9,998 & 5,840 & 3,420 & 0,013 \\
$\mathbf{E}_{\mathbf{4}}(03 / 06 / 13)$ & 10,405 & 4,600 & 2,720 & 0,018 \\
$\mathbf{E}_{\mathbf{5}}(20 / 07 / 13)$ & 28,543 & 4,240 & 0,640 & 0,040 \\
$\mathbf{E}_{\mathbf{6}}(15 / 09 / 13)$ & 6,788 & 3,800 & 5,193 & 0,008 \\
$\mathbf{E}_{\mathbf{7}}(30 / 10 / 13)$ & 3,086 & 14,400 & 15,375 & 0,005 \\
$\mathbf{E}_{\mathbf{8}}(14 / 12 / 13)$ & 38,155 & 6,643 & 0,730 & 0,054 \\
$\mathbf{E}_{\mathbf{9}}(27 / 01 / 14)$ & 57,733 & 18,968 & 1,385 & 0,085 \\
\hline
\end{tabular}

$\mathbf{E}_{1}, \mathbf{E}_{2}, \mathbf{E}_{3}, \ldots \mathbf{E}_{\mathbf{9}}$ - Épocas de coleta no ano de 2013. 


\section{Conclusões}

- Os resultados de atividade decompsitora não se mostraram uteis como indicadores biológicos de áreas degradadas pelo pastejo caprino, pois em algumas épocas de avaliação a AD foi maior nos tratamentos $\left(\mathrm{T}_{1}\right.$ e $\left.\mathrm{T}_{2}\right)$ e em outras, nas testemunhas $\left(\mathrm{T}_{3}\right.$ e $\left.\mathrm{T}_{4}\right)$;

- Sob condições de estresse hídrico, as comunidades microbianas do solo das áreas menos impactadas pelo pastejo $\left(\mathrm{T}_{3}\right.$ e $\left.\mathrm{T}_{4}\right)$ foram mais capazes de decompor a matéria orgânica do solo (AD) mais rapidamente do que àquelas das áreas mais impactadas $\left(\mathrm{T}_{1}\right.$ e $\left.\mathrm{T}_{2}\right)$ sob esta mesma condição, sugerindo a predominância de populações de microorganismos estrategista "k" nessas áreas.

- Os parâmetros microbiológicos aqui estudados, com ênfase para a BM, a $\mathrm{RB}, \quad$ o $\mathrm{qCO}_{2}$ e a relacão $\mathrm{C}_{\text {mic }}: \mathrm{C}_{\text {org }}$ (Experimento 1) e $\mathrm{BM}$ e $\mathrm{C}_{\text {mic }}: \mathrm{C}_{\text {org }}$ (Experimento 2) mostraram-se sensíveis à degradação pelo pastejo, podendo ser utilizados como indicadores ecológicos de áreas degradadas.

\section{Conflito de interesses}

Os autores declaram não haver conflito de interesses.

\section{Referências}

Alexander, M. Introduction to soil microbiology. 2. ed. New York: John Willey \& Sons, 1977.

Andrade, L. A.; Reis, M. G.; Reis, G. G. Classificação ecológica do Estado da Paraíba: interpolação de dados climáticos por aproximação numérica. Revista Árvore, v. 23, n. 1, p. 2332, 1999.

Anderson, J. P. E.; Domsch, K. H. Determination of ecophysiological maintenance carbon requirements of soil microorganisms in dormant state. Biology and Fertility of Soils, v. 1, p. 81-89, 1985.

Anderson, T. H.; Domsch, K. H. Application of ecophysiological quotients $\left(\mathrm{qCO}_{2}\right.$ and $\left.\mathrm{qD}\right)$ on microbial biomass from soils of different cropping histories. Soil Biology and Biochemistry, v. 22, p. 251-255, 1990.

Anderson, T. H.; Domsch, K. H. The metabolic quotient for $\mathrm{CO}_{2}\left(\mathrm{qCO}_{2}\right)$ as a specific activity parameter to assess the effects of environmental condictions, such as $\mathrm{pH}$, on the microbial biomass of forest soil. Soil Biology and Biochemistry, v. 25, p. 393-395, 1993.

Andrews, J. H.; Harris, R. F. r- and k- selection and microbial ecology. In: Marshall, K. L. (Ed.). Advances in microbial ecology. New York: Plenum Press, 1986. p. 99-147.

Bartlett, M. S. Properties of sufficiency and statistical tests. Proceedings of the Royal Statistical Society, Serie A, v. 60, p. 268-282, 1937.

Begon, M.; Harper, J. L.; Townsend, C. R. Ecology: Individuals, populations and communities. 2. ed. New York: Blackwell Scientific Publications, 1990.

Box, G. E.P.; Cox, D. R. An analysis of transformations (whith discussion). Journal of the Royal Statistical Society B, v. 26, n. 2, p. 211-252, 1964.

Campos, H. Estatística experimental não-paramétrica. 4. ed. Piracicaba: Departamento de Matemática e Estatística, ESALQ/ USP, 1983.

Chaves, L. H. G.; Chaves, I. B.; Vasconcelos, A. C. F. Salinidade das águas superficiais e suas relações com a natureza dos solos na Bacia Escola do Açude Namorados. Campina Grande: BNB/UFPB, 2000. (Boletim Técnico).

Chapman, S. J. Inoculum in the fumigation method for soil biomass determination. Soil Biology and Biochemstry, v. 19, n. 1, p. 8387, 1987.

De-Polli, H.; Guerra, J. G. M. C, N e P na biomassa microbiana do solo. In: Santos, G. A.; Camargo, F. A. O. (Eds.). Fundamentos da matéria orgânica do solo: ecossistemas tropicais e subtropicais. Porto Alegre: Genesis, 1999. p. 389-412.

Doran, J. W.; Parkin, T. B. Defining and assessing soil quality. In: Doran, J. W.; Coleman, D. C.; Bezdicek, D. F.; Stewart, B. A. (Eds.). Defining soil quality for a sustainable environment. Madison, SSSAJ, 1994. (Publication, 35). p. 3-22.

Éder-Silva, H. Fitossociologia, regeneração da vegetação e qualidade de sementes em 
áreas de caatinga. Areia: Centro de Ciências Agrárias, Universidade Federal da Paraíba, 2009. (Tese de doutorado).

Effgen, T. A. M.; Passos, R. R.; Lima, J. S. S.; Borges, E. N.; Dardengo, M. C. J. D.; Reis, E. F. Atributos químicos do solo e produtividade de lavouras de cafeeiro conilon submetida a diferentes tratos culturais no sul do Estado do Espírito Santo. Bioscience Journal, v. 24, n. 2, p. 7-18, 2008.

Gama-Rodrigues, E. F.; De-Polli, H. Biomassa na ciclagem de nutrientes. Anais do FertBio 2000: Biodinâmica do Solo, Santa Maria, 2000.

Garcia, C.; Hernandez, T.; Costa, F. Microbial activity soils under Mediterranean environmental conditions. Soil Biology and Biochemistry, v. 26, p. 1185-1191, 1994.

Graziano Neto, F. Questão agrária e ecologia: crítica da moderna agricultura. 3. ed. São Paulo: Brasiliense, 1986.

Grisi, B. M. Biomassa e atividade de microrganismos de solo: revisão metodológica. Revista Nordestina de Biologia, v. 10, n. 1, p. 1-22, 1995.

Grisi, B. M.; Gray, T. R. G. Comparação dos métodos de fumigação, taxa de respiração à adição de glicose e conteúdo de ATP, para estimar a biomassa microbiana dos solos. Revista Brasileira de Ciência do Solo, v. 10, p. 109-115, 1986.

Grisi, B. M. Método químico de medição da respiração edáfica: alguns aspectos técnicos. Ciência e Cultura, v. 30, p. 82-88, 1978.

Jenkinson, D. S.; Ladd, J. N. Microbial biomass in soil: Measurement and turnover. In: Paul, E. A.; Ladd, J. N. (Eds.). Soil Biochemistry. New York: Marcel Dekker, 1981. v. 8. p. 415471.

Jenkinson, D. S.; Powlson, D. S. The effects of biocidal treatements on metabolism in soil. V. A method for measuring soil biomass. Soil Biology and Biochemistry, v. 8, p. 209-913, 1976.

Kruskal, W. H.; Wallis, W. A. Use of ranks is on-criterion variance analysis. Journal of the American Statistical Association, v. 47, n. 260, p. 583-661, 1952.

Levene, H. Robust test for equality of variances. In: Olkin, I.; Ghurye, S. G.; Hoeffding, W.; Madow, W. G.; Mann, H. B.
(Eds.). Contributions to probability and statistics: Essays in honor of Harold Hotteling. California: Stanford University Press, 1960. p. 278-292.

Lima, C. R. Parâmetros ecofisiológicos de Poincianella pyramidalis (Tul.) L. P. Queiroz e sua relação com a variabilidade temporal das chuvas em áreas do Semiárido paraibano. Areia: Centro de Ciências Agrárias. Universidade Federal da Paraíba, 2014. (Tese de doutorado).

Loureiro, D.C. Biomassa microbiana do solo na Amazônia, Mata Atlântica e Antártica. Rio de Janeiro: Universidade Federal Rural do Rio de Janeiro, 2012. (Tese de doutorado).

Luna, R. G.; Andrade, A. P.; Souto, J. S.; Luna, J.G. Análise florística e fitossociológica de quatro áreas de caatinga sob diferentes densidades de caprinos no Cariri Paraibano, Brasil. Revista Brasileira de Gestão Ambiental e Sustentabilidade, v. 5, n. 9, p. 191-229, 2018. https://doi.org/10.21438/ rbgas. 050913

Luna, R. G.; Coutinho, H. D. M.; Grisi, B. M. Evaluation of pasture soil productivity in the semi-arid zone of Brazil by microbial analyses. Brazilian Journal of Microbiology, v. 39, p. 238-240, 2008.

Luna, R. G.; Coutinho, H. D. M. Efeitos de bagaço de cana-de-açúcar e minhocas (Pontoscolex corethrurus) sobre a microbiota do solo (Paraíba, Brasil). Revista Caatinga, v. 21, n. 1, p. 156-161, 2008.

Luna, R. G.; Coutinho, H. D. M. Efeitos do pastejo descontrolado sobre a fitocenose de duas áreas do Cariri Oriental Paraibano. Revista Caatinga, v. 20, n. 2, p. 8-15, 2007.

Luna, R. G.; Grisi, B. M. Biomassa e atividade microbianas de solos cultivados com canade-açúcar, sob efeito da vinhaça. Revista Nordestina de Biologia, v. 11, n. 1, p. 15-29, 1996.

Lynch, J. M.; Panting, L. M. Measurement of the microbial biomass in intact cores of soil. Microbial Ecology, v. 7, p. 229-234, 1981.

Martins, C. M.; Galindo, I. C. L; Souza, E. R.; Poroca, H. A. Atributos químicos e micróbiológicos do solo de áreas em processo de desertificação no semiárido de Pernambuco. Revista Brasileira de Ciência do Solo, v. 34, p. 1883-1890, 2010. 
Mendes, B. V. Alternativas tecnológicas para a agropecuária do semi-árido. São Paulo: Nobel, 1985.

Menezes, R. S. C.; Sampaio, E. V. S. B.; Giongo, V.; Pérez-Marin, A. M. Ciclagem biogeoquímica em ecossistemas terrestres do Bioma Caatinga. Brazilian Journal of Biology, v. 72, n. 3, suppl., p. 643-653, 2012.

Menezes, R. S. C.; Sampaio, E. V. S. B. Simulação dos fluxos e balanços de fósforo em uma unidade de produção agrícola familiar no semiárido paraibano. In: Silveira, L. M.; Petersen, P.; Sabourin, E. (Org.). Agricultura familiar e agroecologia no semi-árido: avanços a partir do Agreste da Paraíba. Rio de Janeiro: AS-PTA, 2002. p. 249260.

Minhoni, M. T. A.; Cerri, C. C. Aplicação da radiação gama na determinação da biomassa microbiana de um solo incorporado com vinhaça. Revista de Microbiologia, v. 18, n. 1, p. 87-92, 1987a.

Minhoni, M. T. A.; Cerri, C. C. Decomposição de vinhaça em solo sob diferentes níveis de umidade: liberação de $\mathrm{CO}_{2}$, formação de biomassa e imobilização de nitrogênio adicionado. Revista Brasileira de Ciência do Solo, v. 11, n. 1, p. 25-30, 1987b.

Odum, E. P. Ecologia. Rio de Janeiro: Guanabara, 1988.

Parente, H. N. Avaliação da vegetação e do solo em áreas de caatinga sob pastejo caprino no Cariri da Paraíba. Areia: Centro de Ciências Agrárias, Universidade Federal da Paraíba, 2009. (Tese de doutorado).

Parkinson, D.; Gray, T. R.; Williams, S. T. Methods for studying the ecology of soil microorganisms. Oxford: Blackwell Scientific Publication, 1971.

Pimentel Gomes, F. Curso de Estatística Experimental. São Paulo: Nobel, 1985.

Powlson, D. S. The effects of griding on microbial and non-microbial organic matter in soil. Journal Soil Science, v. 31, p. 77-85, 1980.

Reis Júnior, F. B.; Mendes, I. C. Biomassa microbiana do solo. Planaltina: Embrapa Cerrados, 2007. (Documentos, 205).
Rencher, A. C.; Christensen, W. F. Methods of multivariate analysis. 3. ed. Hoboken, New Jersey: John Wily \& Sons, 2012.

Sampaio, E. V. S. B. Caracterização do bioma caatinga. In: Gariglio, A. A.; Sampaio, E. V. S. B.; Cestaro, L. A.; Kageyama, P. Y. (Org.). Uso sustentável e conservação dos recursos florestais da Caatinga. Brasília: Serviço Florestal Brasileiro, 2010.

Salcedo, I. H.; Sampaio, E. V. S. B. Matéria orgânica do solo no bioma caatinga. In: Santos, G. A.; Silva, L. S.; Canellas, L. P.; Camargo, F. A. O. Fundamentos da matéria orgânica do solo: ecossistemas tropicais e subtropicais. Porto Alegre: Metrópoles, 2008. p. 419-441.

Shapiro, S. S.; Wilk, M. B. An analysis of variance test of normality (complete samples). Biometrika, v. 52, n. 3/4, p. 591611, 1965.

SUDENE - Superintendência de Desenvolvimento do Nordeste. Dados pluviométricos mensais do Nordeste: Estado da Paraíba. Recife: SUDENE, 1990. (Série pluviometria, 5).

Tomé Jr, J. B. Manual de interpretação de análise de solo. Guaíba: Agropecuária, 1997.

Townsend, C. R.; Begon, M.; Harper, J. L. Fundamentos em Ecologia. Porto Alegre: Artmed, 2006.

Vance, E. D.; Brookes, P. C.; Jenkinson, D. S. Microbial biomass measurements in forest soil: Determination of $k c$ values and tests of hypotheses to explain failures of the chloroform fumigation-incubation method in acid soil. Soil Biology and Biochemistry, v. 19 , n. 6, p. 689-696, 1987a.

Vance, E. D.; Brookes, P. C.; Jenkinson, D. S. Microbial biomass measurements in forest soil: The use of the chloroform fumigationincubation method in strongly acid soil. Soil Biology and Biochemistry, v. 19, n. 6, p. 697-702, 1987b.

Wardle, D. A; Ghani, A. A critique of microbial metabolic quotient $\left(\mathrm{qCO}_{2}\right)$ as a bioindicator of disturbance and ecosystem development. Soil Biology and Biochemistry, v. 27, p. 1601-1610. 1995. 